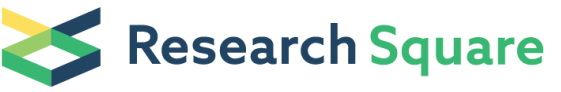 \\ Preprints are preliminary reports that have not undergone peer review. They should not be considered conclusive, used to inform clinical practice, or referenced by the media as validated information.
}

\section{Geometric Morphology and Population Genomics Provide Insights into the Adaptive Evolution of Apis Cerana in Changbai Mountain}

\section{Liu Nannan}

Institute of Special Animal and Plant Sciences of Chinese Academy of Agricultural Sciences

\section{Liu Huamiao}

Institute of Special Animal and Plant Sciences of Chinese Academy of Agricultural Sciences

Ju Yan

Institute of Special Animal and Plant Sciences of Chinese Academy of Agricultural Sciences

Li Xingan

Apiculture Science Institute of Jilin Province

Li Yang

Institute of Special Animal and Plant Sciences of Chinese Academy of Agricultural Sciences

\section{Wang Tianjiao}

Institute of Special Animal and Plant Sciences of Chinese Academy of Agricultural Sciences

He Jinming

Apiculture Science Institute of Jilin Province

Niu Qingsheng

Apiculture Science Institute of Jilin Province

Xing Xiumei ( $\nabla$ xingxiumei2004@126.com )

Institute of Special Animal and Plant Sciences of Chinese Academy of Agricultural Sciences

\section{Research Article}

Keywords: Apis cerana in Changbai Mountain, Wing geometry, Population genomics, Genetic differentiation, Genetic diversity, Adaptive evolution

Posted Date: June 11th, 2021

DOI: https://doi.org/10.21203/rs.3.rs-590369/v1

License: (c) (1) This work is licensed under a Creative Commons Attribution 4.0 International License.

Read Full License 
Version of Record: A version of this preprint was published at BMC Genomics on January 19th, 2022. See the published version at https://doi.org/10.1186/s12864-022-08298-x. 


\title{
Geometric morphology and population genomics provide insights into the adaptive evolution of Apis cerana in Changbai Mountain
}

Liu Nannan ${ }^{1,2}$, Liu Huamiao ${ }^{1}$, Ju Yan ${ }^{1}$, Li Xingan ${ }^{2}$, Li Yang ${ }^{1}$, Wang Tianjiao ${ }^{1}$, He Jinming ${ }^{2}$, Niu Qingsheng ${ }^{2 *}$ and Xing Xiumei ${ }^{1 *}$

\begin{abstract}
Background: Exploration of adaptive evolution of organisms in response to environmental change will offer us a hint to the evolutionary history of species and the underlying mechanisms of adaptation to local environments, thus guiding future conservation programmes. Before the introduction of Apis mellifera in China, Apis cerana was the only species, which could be reared in captivity to obtain products. Moreover, A. cerana in Changbai Mountain is the only ecotype in such a flora.

Result: We investigated the geometric morphological features of $A$. cerana in Changbai Mountain by analysing 300 wing specimens from 30 populations of $A$. cerana in 5 geographic regions. A total of 3,859,573 high-quality SNP loci were yielded via the whole-genome resequencing of 130 individuals from $130 \mathrm{~A}$. cerana geographic populations.
\end{abstract}

Conclusion: Corresponding geometric morphology and population genome confirmed the outstanding evolutionary role of the A. cerana population in Changbai Mountain. Genetic differentiation at the subspecies level exists between populations in Changbai Mountain and remaining geographic regions, and a significant reduction in the effective population size and an excessive degree of inbreeding may be responsible for a substantial loss of population genetic diversity. Candidate genes potentially associated with cold environmental adaptations in populations under natural selection were identified, which may represent local adaptations in populations. Our study provided insights into the evolutionary history and adaptive characteristics of A. cerana in Changbai Mountain, as well as the scientific conservation of this population.

Keywords: Apis cerana in Changbai Mountain, Wing geometry, Population genomics, Genetic differentiation, Genetic diversity, Adaptive evolution

\section{Background}

Nowadays, the number of bees, pollinators, and many other insects has been declining considerably; in particular, the invertebrate pollinators represented by honeybees and butterflies are on the verge of extinction [1, 2]. Apis cerana populations have also experienced severe declines in recent decades [3, 4]. A. cerana in Changbai

*Correspondence: xingxiumei2004@126.com (Xing Xiumei); 1463199779@qq.com (Niu Qingsheng)

${ }^{1}$ Institute of Special Animal and Plant Sciences of Chinese Academy of Agricultural Sciences, Changchun 130112, Jilin Province,

People's Republic of China

${ }^{2}$ Apiculture Science Institute of Jilin Province, Jilin 132108, Jilin Province, People's Republic of China

Full list of author information is available at the end of the article 
Mountain is usually referred to as an ectotype of A. cerana distributed in Northeast China, Korean Peninsula, and even the Russian Far East in a broader sense [5], which wields a role in maintaining and enriching the biodiversity of the terrestrial ecosystem in Changbai Mountain. Specifically, A. cerana in Changbai Mountain mainly serves as the most ideal pollinator for flowering plants in early spring and is capable of swarming in groups to enhance the utilisation of nectar plants in isolated plant and animal habitats [6], and it has adapted to the long winters and short summers of Changbai Mountain, resulting in reproductive and developmental patterns with remarkably fewer breeding generations, which are expressed as a dominant pollination behaviour that relies on population quality rather than just population quantity [3]. As a crucial part of the ecological food chain in Changbai Mountain, a reduction in the number of existing A. cerana bees is bound to affect the survival of upstream predators in the future. In terms of economic value, A. cerana in Changbai Mountain bears excellent traits such as rapid reproduction, strong maintenance of colonies, collection capability, resistance to adversity, and cold tolerance [7]. Thus, it is a popular breeding species among beekeepers, and colony breeding and wild hive nectar harvesting remain as an important source of livelihood for people living in economically underdeveloped mountain areas. Unfortunately, the biotic and abiotic factors, such as ecological invasion of A. mellifera, habitat loss and fragmentation, overexploitation of biological resources, intensive agricultural development, pathogenic microbial infection, overuse of pesticides, global warming, and atmospheric pollution, have caused a massive decline in the population size and distribution density of $A$. cerana in Changbai Mountain [8, 9]; the population size has decreased from more than 40,000 colonies in 1983 to 19,000 colonies in 2008 [10], and then to less than 10,000 colonies at present, with an alarming decline rate of $75 \%$, resulting in an endangered-sustained state. Given the dramatic changes in the genetic structure and diversity of pollinating insects worldwide and environmental factors such as climatic ecology, introduced or translocated exotic colonies may alter the germplasm gene pool of local $A$. cerana in Changbai Mountain in response to the deteriorating ecological conditions. Collectively, the diversity of A. cerana in Changbai Mountain should be further clarified.

The insect wings are two-dimensional and reliably heritable, and wing shape and veins contain a wealth of ecological and behavioural information [11-13]. The measurement analysis based on the geometric morphology of bee wings has been well applied for the identification of species, subspecies, and interspecific levels [14-16], changes in wing size and morphology under environmental stress will help us in exploring its adaptive evolution. Native bees show higher vigour and environmental tolerance than non-native bees [17-19], and A. cerana in Changbai Mountain has developed distinct traits in response to mountain conditions, particularly strong resistance to the cold (able to naturally overwinter in extreme cold conditions at $-40{ }^{\circ} \mathrm{C}$ ). Therefore, in-depth studies are required to understand the genetic basis of population adaptation to temperate continental montane climate.

In this study, we collected samples from 26 sampling sites in Changbai Mountain, covering the entire natural range of $A$. cerana in Changbai Mountain in Northeast China, as well as A. cerana populations from 38 sampling sites in the northern, southern, Qinghai-Tibetan, and northwestern regions. Moreover, resequencing data from 66 A. cerana samples of each ecotype were downloaded from the published literature [20]. A comprehensive analysis of geometric morphometry and population genomics revealed the variation patterns of wing morphology, population genetic diversity, and population history of A. cerana in Changbai Mountain, and helped in identifying candidate genes related to their adaptation to the local cold environment. This study offers an in-depth investigation of the genetic basis and uniqueness of the environmental adaptation of A. cerana in Changbai Mountain and elucidates the endangerment mechanism of the population, thus rendering directions for the scientific and effective conservation of the population. 


\section{Results}

\section{Population geometric morphometric analysis of wings}

A total of 30 geographic population samples (A. cerana) were obtained from 6 northern regions, 6 northwestern regions, 3 Qinghai-Tibetan regions, 8 southern regions, and 7 sampling sites in Changbai Mountain. Among these, samples from Changbai Mountain were from JL, YB, TH, and BS in Jilin Province; BX and HR in Liaoning Province; and RH in Heilongjiang Province (Additional file 1: Table S1).

\section{CS analysis}

The wing size is expressed in terms of the centriod size of the wing. One-way ANOVA revealed a significant difference in CS values of forewings of $A$. cerana distributed in the five geographic regions $(F=54.38, P<0.001)$. The results of multiple tests by the LSD method showed that the populations in the northwestern region, Qinghai-Tibetan region, and Changbai Mountain had larger forewings, and no notable differences were observed between the populations. The Changbai Mountain population differed significantly from the populations in the northern and southern regions in terms of forewing size $(P<0.05)$ (Fig. 1A). Hindwing data demonstrated a highly significant difference in the hindwing CS values among populations from each region $(F=36.08, P<$ 0.001). A. cerana from the Qinghai-Tibetan region, northwestern areas, and Changbai Mountain had larger hindwings, and non-significant differences were observed between these populations, whereas the Changbai Mountain population differed notably $(P<0.05)$ from the northern and southern region populations (Fig. 1B). Stepwise regression analyses indicated that the mean CS values of forewings and hindwings at each sampling site increased with the latitude and altitude $(P<0.05)$, whereas no significant correlation with longitude was observed $(P>0.05)$ (Additional file 1: Table S2).

\section{PCA}

The first two principal components of forewings and hindwings occupied $77.74 \%$ and $83.29 \%$ of the total variance, respectively, both of which were able to illustrate main differences in forewings and hindwings among the geographical populations. Results of forewing PCA showed that BS, JL, TH, YB, RH, and BX populations were concentrated in the positive half-axis of $\mathrm{PC} 1$ and $\mathrm{PC} 2$, whereas the HR population in Liaoning was in the negative half-axis of PC1 and PC2 (Additional file 2: Fig. S1). Results of hindwing PCA showed that BS, JL, TH, $\mathrm{YB}, \mathrm{RH}$, and HR populations were concentrated in the positive half-axis of $\mathrm{PC} 1$, whereas the $\mathrm{BX}$ population in Liaoning was in the negative half-axis of PC1 (Additional file 2: Fig. S1). Taken together, a certain degree of wing morphological differentiation was observed within $A$. cerana in Changbai Mountain, with no significant differentiation observed between the Jilin and Heilongjiang populations and significant differentiation observed between Liaoning populations.

\section{TPS analysis}

Based on the analyses of principal components, TPS analysis was performed on the morphological data (Fig. 2; Additional file 3: Fig. S2). A comprehensive analysis was conducted on the locations of the landmarks of relative contraction and relative relaxation of the forewings of each population of $A$. cerana in Changbai Mountain. The main sites of forewing variation were concentrated in the LM9-10 and LM1-3, that is, the intersection of the radiomedial crossvein with the mediae and intersection of the medio-cubital crossvein with the mediae, as well as the intersection of the vannal vein with the cubitus-vannal vein, intersection of the mediae-cubitus vein with the cubitus-vannal vein, and intersection of the mediae with the cubitus. The hindwing variation was mainly 
concentrated in the LM3-6, that is, the intersection of the mediae with the cuibitus, intersection of the radial vein with the radial sector, and two intersections of the radiomedial crossvein with the mediae and radial sector [21].

\section{Population genetic structure analysis}

Samples were collected from 9 ecotypes of $A$. cerana [10], of which samples from Changbai Mountain were procured covering the entire natural range of the populations (Fig. 3, Additional file 4: Table S3). Whole-genome resequencing yielded a total of $243.37 \mathrm{~Gb}$ of data. Compared with the reference genomes, the average comparison rate of the population samples was $93.91 \%$ and the average sequencing depth was $13.32 \times$ (Additional file 5: Table S4). For the population evolution analysis, we also downloaded $165.44 \mathrm{~Gb}$ of resequenced data from 66 A. cerana samples of various geographic ecotypes from the published literature (Additional file 6: Table S5). After quality control, a total of 3.86 million SNPs were identified, of which 253,656 were in exonic regions and 52,161 were in non-homologous regions (Additional file 7: Table S6), and a total of 2,237,786 Indels were detected, of which 15,588 were in exonic regions (Additional file 7: Table S7).

Population genetic structure and population descent information were first constructed using ADMIXTURE [22] (Fig. 4A). The result showed that when $K=2-5$, JL01-07, JL09-14 and HL01-05 in A. cerana in Changbai Mountain were from the same ancestor. The pure lineage forms a single taxon, while all the Liaoning population and JL08, JL15, JL16, and JL17 are of mixed lineage and have different ancestral origins. In particular, when $K=$ 4 and $K=5$, the origin of the Liaoning population was more complex, with individual samples containing a mixture of 3 or more ancestral subgroups, whereas JL08, JL15, JL16, and JL17, which showed different degrees of admixture, all came from the Ji'an region of Jilin Province. The best $K$ value was 4 , all regions were divided into 4 genetic components, the Tibetan and Hainan populations were separated from the large population set, whereas the Southern populations showed a more highly mixed state than the Northern and Northwestern populations due to their richness in geographic ecotypes. Afterwards, PCA was performed using GCTA [23] (Fig. 4B), and the results of all three PCAs separated most of the Changbai Mountain populations and clustered them together separately (Additional file 8: Fig. S3), whereas the Liaoning population and Ji' an population were mixed with those from the northern, northwestern, Qinghai-Tibetan, and southern regions, which were considerably less genetically related to pure populations of Changbai Mountain, further supporting the results of genetic structure analysis. Next, using the obtained SNPs, a phylogenetic tree of Changbai Mountain population with other populations was constructed using A. mellifera as an outgroup [24] (Fig. 4C), with all Jilin population sclustered with Heilongjiang populations, and the Liaoning population was partly separated from the Changbai Mountain population and mixed with other regional populations, while the other part was clustered with the Ji'an population and was more closely related to the Northern populations, showing its relatively complex genetic background, which is consistent with the results of the genetic structure and PCA.

\section{Genetic differentiation and genetic diversity}

The $\pi$ and Fst values of "pure populations" of $A$. cerana in five geographic regions and in Changbai Mountain were statistically analysed. Among A. cerana populations in each geographical region, the highest nucleotide diversity $(\pi)$ was found in the Northern populations and the lowest in the Changbai Mountain populations (Fig. $5 \mathrm{~A})$. The highest $\pi$ was found in the Liaoning population and the lowest in the Heilongjiang population among Changbai Mountain populations (Fig. 5B). Considering the analysis results of the population genetic structure, the Liaoning population was hypothesised to have acquired a large number of genetic lineages from the geographic ecotype lineages of the northern and southern regions, and the influx of new alleles led to the highest genetic 
diversity of the A. cerana population in Changbai Mountain. Paired Fst ranged from 0.0094 to 0.2609 , with an average of 0.1133 , and A. cerana populations in various regions exhibited moderate genetic differentiation [20, 25, 26]. The mean Fst was 0.2294 between the Changbai Mountain population and the A. cerana populations from the northern, northwestern, southern, and Qinghai-Tibetan regions, showing a high degree of genetic differentiation (Table 1). Paired Fst for samples from each region within the Changbai Mountain populations ranged from -0.0031 to 0.2030 (Table 2). Fst for Jilin populations from BS, JL, TH, and YB were all below 0.02, indicating an extremely low degree of genetic differentiation. The average Fst between the Heilongjiang and Jilin populations was 0.1002 , which indicated moderate to low differentiation. Notably, the Liaoning population reached a high degree of genetic differentiation, with an average Fst of 0.1506 .

We evaluated expected heterozygosity (He), observed heterozygosity (Ho), inbreeding coefficient (F), and linkage disequilibrium (LD) for each geographic population of A. cerana, and A. cerana in Changbai Mountain had the lowest He, highest Ho, and highest F (Table 3), indicating that they had a low level of genetic diversity, a high level of genetic differentiation from other geographic populations of A. cerana, and a high degree of inbreeding. LD analyses showed that the Changbai Mountain population exhibited the slowest LD decay (Fig. 6). Presumably, inbreeding decline may be responsible for the lowest genetic diversity, which is consistent with the results of the analysis of genetic diversity indicators.

\section{Demographic history}

The PSMC model is a reliable method for exploring the long-term trajectory of the population size [27]. The quantitative variation in the effective population size of $A$. cerana in various regions, including Changbai Mountain populations, coincided with the cyclical variation in historical global temperature, which peaked during the most recent major interglacial period of the Pleistocene, approximately 110-133 million years ago, when the global climate was warm, followed by a sharp decline, consistent with the findings of Chen et al. [20] who reported that the effective population size of $A$. cerana peaked at MIS5. The difference lied in the fact that the $A$. cerana population in Changbai Mountain exhibited a more moderate expansion and contraction of the effective population and the population size was at a lower level than A. cerana populations in other regions (Fig. 7A).

Available evidence demonstrated that the $A$. cerana population was affected by cyclical climate changes during the Quaternary ice age [28], and that volcanic eruption activity at Tianchi, Changbai Mountain, continued throughout the Quaternary [29, 30], inevitably impacting the population evolution and distribution patterns of the existing A. cerana population in Changbai Mountain. According to the Quaternary glacial remains around the Tianchi volcanic cone, the basic geomorphic features of the Tianchi caldera were formed in the MIS4 and were maintained to the present day after basic stereotypes [30], and the fossil glacier scale of the last glacial period was larger in the early (MIS4) than in the late (MIS2) [31], which implied that the paleoclimate of Changbai Mountain was greatly influenced by glaciation at that time. We therefore focused on labelling the changes in the number of effective population size in the MIS4.

The SMC++ method is an extension of the PSMC method for estimating more precisely the effective population size within 10,000 years [32]. From the MIS4 to the Holocene period, the A. cerana population in Changbai Mountain experienced two significant population contractions and one significant population expansion compared with populations in other regions (Fig. 7B). The population decline during the MIS4, which lasted until the last glacial maximum of approximately $15 \mathrm{ka} \mathrm{BP}$, is presumed to be mainly due to the paleoglaciation, grand development of the ice sheet, low snowline, and small dust flow, indicative of a cold and wet climate [33], and the 
harsh natural ecological climate brought about a population decline, which corroborated with the analysis results obtained by the PSMC method. The Changbai Mountain is crowned as the largest active volcano in China for its violent blast eruptions in the Holocene. A massive explosive eruptive activity occurred at Tianchi volcano during the Tianwenfeng period at $50.6 \mathrm{ka} \mathrm{BP}$, which formed the first breakout crater [34], and climate change and ecological degradation caused by strong volcanism might have aggravated the decrease in $A$. cerana populations.

The effective size of the A. cerana population in Changbai Mountain increased significantly for once from the last glacial maximum of $15 \mathrm{ka} \mathrm{BP}$ to the Holocene, indicating that global warming was beneficial to the Changbai Mountain population. The period of maximum extent of continental icesheet was $18 \mathrm{ka} \mathrm{BP}$, and since then, glaciers began to retreat. The Holocene warm period in the northeast was the best period for vegetation development, and the enhanced summer monsoon precipitation due to warming led to ecological recovery [35]. Global warming accelerated the rapid expansion of honeybee populations.

The effective population size declined significantly again at approximately 5-2 ka BP. During the middle Holocene period, approximately 8000-2500 years ago, the climate was warm and humid, the temperature at its peak may have been more than $2{ }^{\circ} \mathrm{C}$ higher than modern times [36], the ecological conditions were favourable for species reproduction, while the effective population of honeybees drastically reduced. According to volcanic geology and historical records, there have been several eruptions of the Changbai Mountain 5000 years ago [37, 38], which produced ash drifts up to thousands of kilometers away and deposition thicknesses of several centimeters [39, 40], causing large-scale biological extinctions and serious impacts on the global climate, environment, and ecology [41-43]. In addition, a small peak in the number of hardy plants such as pine, spruce, fir, and birch occurred in the Changbai Mountain around 5000 years ago, which may indicate a climatic cooling event [44], and a similar European Ulmus decline occurred in the pollen fossil belt 5000 years ago in eastern China [45]. Therefore, it is reasonable to speculate that the combination of volcanic heat and abnormal cooling led to a significant decline in the effective population size of $A$. cerana in Changbai Mountain during the $5 \mathrm{ka}$ BP period.

\section{Selective elimination analysis}

We performed a selective elimination analysis between Changbai Mountain population and Hainan population. Genes showing positive selection signals in the genome were screened, and genes were categorised according to the reference genome for functional gene annotation and KEGG and GO functional categories (Fig. 8A). A total of 273 genes were selected in the Changbai Mountain population(Additional file 9: Table S8), and they were involved in $1621 \mathrm{GO}$ and 40 KEGG pathways, with 99 GO and 5 KEGG pathways significantly enriched at a threshold of $P \leq 0.05$ (Additional file 10: Table S9; Table S10).

A collation of the top $20 \mathrm{GO}$ and KEGG pathways involved in selective clearance signalling by Fst values (Additional file 11: Table S11) revealed that many GO entries and KEGG pathways are associated with cold adaptation in insects [46, 47]. In the GO classification, the selected signals were mainly enriched in the metabolism of energy substances, synthesis and production processes, transmembrane transporter activity, ion transport, channel activity, homeostasis, localisation, regulation, binding, enzyme activity, response, signal transduction, and sensory perception. Ether lipid metabolism, glycerophospholipid metabolism, and sphingolipid metabolism are the KEGG pathways in which higher Fst values are jointly involved by selective genes. These participating genes may have potential contributions to the evolution of environmental adaptations of A. cerana in Changbai Mountain. Moreover, there are multiple shared genes among these pathways, which means that these pathways can possibly work synergistically through these shared genes to accomplish this physiological activity 
of cold acclimation.

The pathway enrichment of the selected genes combined with the functional annotation of the genes themselves resulted in the identification of several highly enriched functional categories, including structural constituent of cuticle (4), zinc ion binding (4), serine/threonine-protein kinase (5), lipid storage droplets surface-binding protein (4), and G-protein-coupled receptor 1 family (4) (Additional file 9: Table S8). The Tibetan and Changbai Mountain populations belong to the cold-tolerant species, and the same method was used to perform the selective elimination analysis between the Tibetan and Hainan populations (Fig. 8B). In total, 163 selected genes were obtained for the Tibetan population, and 22 genes were identical to the selected region of the Changbai Mountain population (Additional file 12: Table S12), of which two enriched genes belonged to the G-protein-coupled receptor 1 family, and it was speculated that this gene family might wield a role in the genetic basis of cold adaptation in the Changbai Mountain population.

\section{Discussion}

The pattern of changes in insect size with latitude or altitude is consistent with three scenarios: Bergmann's rule, Converse Bergmann's rule, or absence of the rule of gradual change, and a comparable number of research results have supported these three views [48, 49]. The present study showed that CS values of $A$. cerana populations in each geographical region increased with latitude and altitude, and the pattern of change in wing size was in accordance with the Bergmann's rule. Larger wings imply larger insects who adapt to cold conditions at high altitudes and long overwintering periods through an increase in body size [50, 51]. The Changbai Mountain is located at a high latitude and low altitude area with a temperate continental mountainous climate.The cold environment challenges the thermoregulation, flight, and reproductive abilities of the Changbai Mountain population, which has larger CS for its forewings and hindwings, implying that individuals can carry more weight in flight [52], have a greater foraging range [53], and have an increased nectar collection ability [54, 55]. Thus, the superiority of the Changbai Mountain population in terms of wing and body sizes plays a role in their survival competition.

The morphology and size of insect wings can be used as indicators of environmental stress or environmental conditions [56, 57]. We found that the differences between the wing morphology of Changbai Mountain population and the average wing morphology of $A$. cerana were stably concentrated in several sites. As for the forewing, LM1-3 are at the base of the wing, and the thickness of the wing membrane gradually decreases from the base to the end of the wing, while the base of the wing in the thicker region of the wing membrane is the main landing zone in flight [58]. The apparent expansion of the Changbai Mountain population at this location could enhance its flight, which may be compatible with foraging activities to survive in the cold environment. Worker bees usually have a bifurcated protrusion on the radiomedial crossvein and a high cubital index of the forewing, which is a major feature that distinguishes the Changbai Mountain population from other ecotype populations (Fig. 9), and this feature is often used as a bee morphological identification index for genetic classification studies [10]. Zhou et al. [59] confirmed significant morphological differences and similar degrees of differentiation in samples collected from Jilin, Hainan, and Shaanxi, with the cubital index of Jilin A. cerana being significantly different from that of the other two honeybees, and suggested that the Jilin population may be a novel subspecies. Our experimental results indicated that LM9-10, the location of its strong constriction compared with the average wing morphology of $A$. cerana, is exactly the sites where the small protrusion vein on the radiomedial crossvein and the cubital index were determined [10]. Such an exciting finding further proved the specificity of $A$. cerana in 


\section{Changbai Mountain.}

The wing veins of insects are rich in phylogenetic and evolutionary information and have tended to decrease during the evolutionary history of Hymenoptera [21]. The veins of the hindwings of $A$. cerana underwent significant variation after the sealed broods of $A$. cerana were incubated constantly at a low temperature until emergence, and the increased wing veins were likely tobe those that disappeared during evolution [60, 61]. The variation in the hindwings of the Changbai Mountain population occurred mainly on the radial sector and mediae, which were consistent with the occurrence of both newbron veins and protrusion veins in honeybees after the sealed brood with cryogenic treatment. During the long evolution, the harsh ecological environment in Changbai Mountain may have influenced the development of sealed brood of A. cerana to some extent, and the local climatic environment may account for the specialisation in wing morphology. The morphological variation on the radiomedial crossvein of the forewing was preserved as stable genetic marker information, reflecting the evolutionary traces of the Changbai Mountain population, which requires more molecular biological data to confirm this hypothesis. On the other hand, geometric morphometric analyses revealed a certain degree of wing morphological differentiation already within the Changbai Mountain populations, with the Jilin population (BS, JL, TH, YB) and Heilongiang population (RH) showing roughly the same sites of variation in forewings and hindwings without significant differentiation, while Liaoning populations (BX and HR) showed greater changes in the sites of variation and significant differentiation.

The genetic differences between the Changbai Mountain population and Northern, Northwestern, Southern, and Qinghai-Tibetan populations matched the level of genetic differences among subspecies [25, 26, 62], reflecting the special status of populations in the evolutionary process. Chen et al. [20] supported that differentiation between the more isolated populations (ecotypes) occurred at the subspecies level. Some researchers have suggested that A. cerana in Changbai Mountain were morphologically similar to the Korean and Japanese populations, and may be classified as the same taxon [63,64]. Gene flow blocking is responsible for population differentiation, prompting differentiation into independent populations that produce genetic traits adapted to the local environment [65]. A recent study revealed the population structure and rapid radiation history of oriental honeybees in mainland Asia, where northeastern populations radiated from a central ancestral group with 6 peripheral subspecies, including Taiwan, Hainan, Bomi, Aba, and Chinghai, and adapted independently to different habitats [66]. A. cerana in Changbai Mountain bears varying degrees of genetic differentiation within its population. The genetic differences were negligible among the local populations of BS, JL, TH and YB, which exhibited a low genetic differentiation compared with Heilongjiang population, whereas a significant and major genetic differentiation was noted between the Jilin and Liaoning populations. Genomic infiltration of A. cerana ecotypes, especially of those from northern and southern regions, may dominate Liaoning population, with mixed lineage origins, as strongly evidenced by the results of the wing geometry morphometric and genetic structure analyses. Moreover, populations in the core area of Changbai Mountain is under threat from the outer reserves; in particular, the Ji' an population, which is in the Jilin germplasm core area, is subjected to genetic infiltration from other geographical ecotypes, and the uncontrolled introduction of exotic colonies poses a serious threat to the purity of the local population.

A certain number of pure wild bee colonies are present in Changbai Mountain, mostly in the hollow caves of trees, rock caves in steep mountain cliffs, rock crevices, underground caves, and other hidden places. Oriental honeybees have the germplasm characteristic of flight escape, and a certain number of wild colonies are obtained from various reared colonies and are constantly replenished. In recent decades, human capture and the outbreak of 
sacbrood virus have greatly changed the population dynamics of oriental honeybees in Changbai Mountain [67, 68]. The wild population suffered a devastating loss, resulting in an increase in the proportion of the wild colonies obtained from the managed colonies. A large reduction in the number of wild bees leads to a decrease in the effective population, which may directly lead to a decrease in the genetic diversity of the Apis cerana in Changbai Mountain, and a low level of genetic diversity tends to increase inbreeding. The previous analysis of genetic diversity of A. cerana in Changbai Mountain, which was based on SSR and mtDNA markers, also reflected the current situation of a single genetic structure and low genetic diversity $[65,69,70]$. It has the highest degree of $\mathrm{LD}$, which is likely to have experienced a serious evolutionary bottleneck event, while showing a very low genetic polymorphism and a slow level of decay. The results of population history analysis show that biogeography and climate change have seriously affected the Changbai Mountain population, and glaciation and local volcanic events have likely brought about the bottleneck effect of population history. The "Northern cerana" group of oriental honeybees extends from northern Afghanistan and Pakistan to northwest India, southern Tibet, northern Myanmar, China, and then northeastward into North Korea, the Russian Far East, and Japan [5], while the oriental honeybee is not native to Russia, it has been found in the Ursuli (or Primorsky) region of the Russian Far East and in eastern Mongolia [71, 72]. These areas are likely to be refuges after the bottleneck of the population.

The selection elimination regions were detected by Fst and $\pi$. We excavated the selected genes in the evolution of Changbai Mountain population from multiple perspectives. Genes subjected to strong selective elimination signals are mainly involved in GO pathways related to the synthesis and metabolic processes of energy substances, transmembrane transport, channel activity, ion transport, enzyme activity, localization, regulation, response to stimulus, locomotor activity, homeostasis, and repair, which contributed its potential power to the evolution of cold environment adaptation in the Changbai Mountain population. The KEGG pathways involved in the selected genes with a high FST value are all related to the metabolism of lipid energy substances, and energy metabolism is crucial for the cold resistance of honeybees [47, 51]. The population inhabited Changbai Mountain for a long time and its overwintering period lasts for half a year, which is a longer period of cold domestication than the colonies living in the warm environment experience in the south, and its cold tolerance is exercised for a long time to develop superior resistance to cold. Cold tolerance exercise in insects is normally an energy-consuming process, and cold tolerance adaptive traits are genetically and evolutionarily stable [73], indicating that the population has evolved a complete adaptive capacity for storage and metabolism of cold-resistant substances under long-term low temperature stress. In terms of functional annotation of selected genes, the G-protein-coupled receptor family is the largest superfamily of receptors on the cell surface that translates sensory inputs into cellular responses and is essential for regulating the physiology and behaviour of organisms in response to their environment [74]. During the overwintering period, populations are not only exposed to cold stress but also to additional biotic and abiotic stresses such as starvation, oxygen deprivation, energy depletion, and threats from parasites and pathogens. Insect G-protein-coupled receptors are involved in the regulation of numerous key physiological and biochemical processes; they bind to chemicals in cellular surroundings during cell signalling and activate a series of signalling pathways that ultimately cause changes in the cellular state in response to external environmental stresses.

The declining effective population size and loss of genetic diversity explained the main intrinsic factors for the endangerment of $A$. cerana in Changbai Mountain, and inbreeding has been shown to negatively affect traits such as nectar production and swarming behaviour [75]. Frequent queen breeding and colony trade activities promote gene flow between native and commercial populations; however, it yet may lead to irreversible loss of local adaptations in native populations, genetic homogenisation, and pose a risk of genetic contamination [76, 77]. 
Therefore, local subspecies must be effectively protected. First, it is imperative to strengthen the management of core germplasm reserves and restrain introductions of colonies from non-germplasm core areas to reduce the risk of genetic infiltration of native bees and introduction of pathogens and/or parasites. Second, the feasibility of controlling queen mating should be considered, special areas in the core area where local bees can gather and where mating can be controlled should be designated. Third, conducting basic research on population reproduction, foraging, mating behaviour, and production traits is necessary for successful population conservation, and using appropriate molecular biology techniques to assess the native honeybee population size and regular genetic monitoring of populations will help maintain their purity. Finally, wild colonies experience different selection pressures relative to managed colonies, which can provide insights into the process of adaptation to local environmental conditions, and these honeybee can serve as a genetic reserve gene pool for future managed populations.

\section{Conclusions}

The body and wing sizes of $A$. cerana in Changbai Mountain showed a gradual change with altitude and latitude, in accordance with the Bergmann's rule in ecogeography. Geometric morphometric methods were utilised to analyse the morphological variation patterns of the forewing and hindwing, providing a novel morphological evidence for the evolutionary study of populations. Genetic differences were observed between Changbai Mountain population and other geographic populations at subspecies level, which has a lower effective population size and genetic diversity, and a higher degree of inbreeding. Selected genomic regions associated with adaptation of populations to cold environments were identified, and these genes may represent local adaptations of population, which serve as excellent candidates for further research. Geometric morphological and colony genomic evidence confirmed the special evolutionary status of $A$. cerana populations in Changbai Mountain, which will contribute to future conservation programmes.

\section{Methods}

\section{Honeybee collections}

A. cerana samples were collected from 64 apiaries in 5 geographical regions of China, including northern, northwestern, Qinghai-Tibetan, southern regions, and Changbai Mountain. All samples were taken from germplasm reserves or original rearing colonies, with priority given to samples from wild hives (e.g. tree cave hives) and traditional-type hives (e.g. tree barrel hives). In total, 1-10 colonies were taken from each sampling site, and 30-50 worker bees were randomly taken from each colony. The samples were transported in anhydrous ethanol and stored in an ultra-low temperature refrigerator at $-80^{\circ} \mathrm{C}$.

\section{Dissection and collection of morphometric data}

Ten worker bees were randomly selected from each sampling site, and a total of 300 honeybee samples were collected from 30 sampling sites, which basically covered all climatic regions in China. The right forewings and hindwings of the worker bees were removed with forceps, and the wings were fixed by pressing them in the middle using two slides to make slide specimens. The specimens were then photographed using a German Leica LEICA-M165FC fluorescence microscopy imaging system. During image acquisition, all specimens were photographed under the same standard and scale.

The forewings and hindwings of the samples were digitally marked using TPS Util and TPS Dig software, respectively [78, 79], with 20 points for the forewing and 10 points for the hindwing (Fig. 9). All the landmarks 
were the intersection points of the stable wing veins $[16,80]$. The obtained data of the wings were input into Coordgen 6.0, with the 1st and 7th coordinate points as the baseline for the forewings and the 2nd and 10th coordinate points as the baseline for the hindwings. The coordinate values of the landmark were overprinted using the Generalized Procrustes Analysis to remove the influence of non-morphological factors, while the average profile information of each population was calculated on the basis of the GLS method [80].

\section{Geometric morphometric analysis of wings}

One-way ANOVA and LSD multiple tests were performed using SPSS software, and the results were presented as box plots. The correlation between wing size variation in elevation, longitude, and latitude was determined by calculating the CS of the wing and regressing the geographical information of the sample sites where they were located. The PCA and TPS analyses were performed using PAST software [81] to analyse the differences in landmarks and visualise legends to assess the differences in the wing vein morphology between A. cerana in Changbai Mountain and other geographical populations.

\section{Sequencing, quality control, and alignment reference genome}

One workerbee was randomly selected from each colony in the sampling site for whole-genome resequencing. First, genomic DNA was extracted and quantified precisely, and DNA samples with a total volume of $\geq 1.5 \mu \mathrm{g}$ were used for library construction. The inspected DNA samples were randomly broken into 350-bp-long fragments through Covaris, followed by high-quality library construction using the TruSeq Library Construction Kit, the library was prepared through various steps such as end repair, ployA tailing, sequencing junction, purification, and PCR amplification. The constructed library was sequenced by Illumina. Qubit3.0 was then used for preliminary quantification, and the insert size of the library was measured by Agilent 2100 after diluting the library to $1 \mathrm{ng} / \mu \mathrm{L}$. Then, the effective concentration of the library was accurately quantified by Q-PCR. Finally, according to the effective concentration of library and data output requirements, the Illumina platform was used for PE150 sequencing.

The raw image data obtained from sequencing were transformed into sequence data by base calling, filtered to obtain high-quality valid data, and compared to the reference genome [83] using BWA [82] software (set parameter mem -t 4 -k $32-\mathrm{M}$ ), and the comparison result duplicates were removed by SAMtools [84] (set parameter rmdup). The reference genome version used was GCA_002290385.1_ApisCC1.0_genomic.fa with a genome size of 228,791,026 bp.

\section{Variation detection and annotation}

A. mellifera was used as the outgroup for phylogenetic tree construction, and a total of 135 samples were collected for variant detection. SNP detection was performed using SAMtools [84], and high-quality SNPs were filtered and screened by (1) SNPs with a support number above 3, (2) missing ratio $<10 \%$, and (3) minor allele frequency $>$ $1 \%$. The SNP detection results were then functionally annotated using ANNOVAR software.

\section{Population structures}

ADMIXTURE was used to study the genetic structure of the populations. Based on the results of the population structure analysis, the samples from Liaoning and Ji'an no longer possessed the pure Changbai lineage and were therefore excluded from the calculation of the genetic diversity index, LD analysis, population history, and selection elimination analysis, and the SNP data from the purebred Jilin and Heilongjiang samples were selected. GCTA64 software was used for PCA, and the first three major components were plotted. The distance matrix was 
calculated using Treebest-1.9.2 software, and based on this data, a phylogenetic tree was constructed using the neighbour-joining method, the bootstrap values of the tree were obtained after up to 1000 calculations.

\title{
Population genetics analyses
}

VCFtools was used to calculate $\pi$, Fst, He, Ho, and F. The parameter for calculating $\pi$ was set to "--window-pi 40000 --window-pi-step 20000". The parameter for calculating Fst was set to "--fst-window-size 40000 --fst-window-step 20000". He, Ho, and F were calculated using the het command. Individual hom/alt was calculated by vcftools --het, and for the output data, het and hom loci were respectively compared to the total genome length of the previous species by removing N (209222734) and multiplying by $100 \%$.

\section{Linkage disequilibrium analysis}

LD analysis was performed using Haploview software. The SNP spacing on the genome was fitted to the linkage disequilibrium coefficient $\left(\mathrm{r}^{2}\right)$, and data with $\mathrm{r}^{2}$ greater than 0.1 were used as the decay value of the LD.

\section{Effective population size}

PSMC and SMC ++ methods were used. The parameters were set as $-\mathrm{N} 30$-t15 -r 5 -p $4+25 * 2+4+6$, the mutation rate was set as $5.3 \times 10^{-9}$, and the generation time was set as an estimate of 1 year [51]. The X-axis represents the time from the present, and the Y-axis represents the effective population size.

\section{Selective sweep}

A. cerana samples from Changbai Mountain, Hainan, and Tibet were selected for selection elimination analysis. $\theta \pi$ was calculated with a $10 \mathrm{~K}$ sliding window. GO enrichment analysis was compared to the Pfam database to obtain GO terms, and enrichment analysis was performed using goseq. KOBAS was adopted for KEGG enrichment, the species used was A. mellifera, and the BlastX parameter was set -evalue 1e-5 -m8.

\begin{abstract}
Abbreviations
A. cerana: Apis cerana; A. mellifera: Apis mellifera; BS: Baishan; BX: Benxi; CS: Centroid size; DNA: Deoxyribonucleic acid; F: Inbreeding coefficient; Fst: F-statistics, Genetic differences among population; GO: Gene ontology; He: Expected heterozygosity; Ho: Observed Heterozygosity; HR: Huanren; JL: Jilin; KEGG: Kyoto Encyclopedia of Genes and Genomes; KOBAS: KEGG Orthology Based Annotation System; LD: linkage disequilibrium; LM: Landmark; MIS: Marine isotope stages; PC: Principal component; PCA: Principal component analysis; $\pi$ : Nucleic acid diversity; PSMC: Pairwise sequentially markovian coalescent; RH: Raohe; SMC++: Sequentially markovian coalescent TH: Tonghua; TPS: Thin plate spline; YB: Yanbian.
\end{abstract}

\section{Supplementary Information}

Additional file 1: Table S1. Sample information of wing geometry and standard morphometrics. Table S2. The result of the stepwise regression analysis of wing size and geographic information.

Additional file 2: Figure S1. The first principal component (Component 1) and the second principal component (Component 2) Min. Spanning tree of the wing of $A$. cerana.

Additional file 3: Figure S2. The TPS result of forewing and hindwing of A. cerana populations in Changbai Mountain.

Additional file 4: Table S3. Sample information of sequencing.

Additional file 5: Table S4. Summary of sequencing data depth, coverage and quality of 64 samples.

Additional file 6: Table S5. Geographic information, sequencing depth and coverage of 66 downloaded samples.

Additional file 7: Table S6. Result of SNP annotation. Table S7. Result of Indel annotation. 
Additional file 8: Figure S3. The result of PCA.

Additional file 9: Table S8. Selected genes of $A$. cerana population in Changbai Mountain.

Additional file 10: Table S9. Enriched GO terms of the selective sweep genes of $A$. cerana populations in Changbai Mountain $(P<0.05)$ Table S10. KEGG enrichment of the selective sweep genes of $A$. cerana populations in Changbai Mountain $(P<$ $0.05)$

Additional file 11: Table S11. The top 20 genes of FST value participate in Go term.

Additional file 12: Table S12. Common selected genes of $A$. cerana populations in Changbai Mountain and Qinghai-Tibet.

\section{Declarations}

\section{Ethics approval and consent to participate}

All animal experiments were performed in accordance with the "Guidelines for Experimental Animals" of the Ministry of Science and Technology (Beijing, China), and approved by the Institutional Animal Care and Use Ethics Committee of Institute of Special Animal and Plant Sciences of CAAS.

\section{Consent for publication}

Not applicable.

\section{Availability of data and materials}

All sequencing data generated during the current study have been submitted to the NCBI Short Read Archive (SRA) under the BioProject accession number PRJNA730587. All other data analysed in the present study are included in this published article (and its Supplementary Information files).

\section{Competing interests}

The authors declare that they have no competing interests.

\section{Funding}

This work was financially supported by Funds of Central government guided local science and technology development funds for Jilin Province basic research project (No. 202002060JC), and Jilin Province science and technology development Project (No. 20200703002ZP). The funders provided the financial support to the research, but had no role in the design of the study, analysis, interpretations of data and in writing the manuscript.

\section{Authors' contributions}

XX, NQ and LN designed and coordinated the research. LN and HJ conducted laboratory work of wing geometric morphology. LH, LX, JY, LY and WT analyzed the sequencing data. XX, NQ and LN drafted the paper. All authors read and approved the final manuscript.

\section{Acknowledgements}

The authors are especially grateful to all beekeepers, friends of apiculture in the sampling area, my colleagues and other contributors who provided the valuable samples for this work. We also wish to give special thanks to all technicians in the project, involved State Key Laboratory for Molecular Biology of Special Economic Animals and Key Laboratory for Bee Genetics and Breeding of Jilin Province. Finally, we would also thank Novegene Technology Company Limited for their help. 


\section{References}

1. Potts SG, Imperatriz-Fonseca V, Ngo HT, Aizen MA, Biesmeijer JC, Breeze TD, Dicks LV, Garibaldi LA, Hill R, Settele J et al. Safeguarding pollinators and their values to human well-being. Nature. 2016;540(7632):220-9. http://dx.doi.org/10.1038/nature20588.

2. Aslan CE, Zavaleta ES, Tershy B, Croll D. Mutualism disruption threatens global plant biodiversity: a systematic review. PLoS One. 2013;8(6):e66993. https://doi.org/10.1371/journal.pone.0066993.

3. Theisen-Jones H, Bienefeld K. The Asian honey bee (Apis cerana) is significantly in decline. Bee World. 2017;93(4):90-7. https://doi.org/10.1080/0005772X.2017.1284973.

4. Chen C, Liu ZG, Luo YX, Xu Z, Wang SH, Zhang XW, Dai RG, Gao JL, Chen X, Guo HK et al. Managed honeybee colony losses of the Eastern honeybee (Apis cerana) in China (2011-2014). Apidologie. 2017;48(5):692-702. http://dx.doi.org/10.1007/s13592-017-0514-6.

5. Radloff SE, Hepburn C, Hepburn HR, Fuchs S, Hadisoesilo S, Tan K, Engel MS, Kuznetsov V. Population structure and classification of Apis cerana. Apidologie. 2010;41(6):589-601. http://dx.doi.org/10.1051/apido/2010008.

6. Corlett RT. Flower visitors and pollination in the oriental (Indomalayan) region. Biol Rev Camb Philos Soc. 2004;79(3):497-532. http://dx.doi.org/10.1017/s1464793103006341.

7. Liu NN, Wang XM, Li JL, He JM. Production performance and biological characteristics of Changbai mountain Chinese bee during the blooming periods of Tilia. Special Wild Economic Animal and Plant Research. 2020;42(6):5-9. http://doi.org/10.16720/j.cnki.tcyj.2020.06.002

8. Brown MJF, Paxton RJ. The conservation of bees: a global perspective. Apidologie. 2009;40(3):410-6. http://dx.doi.org/10.1051/apido/2009019.hal-00892052.

9. Zayed A. Bee genetics and conservation. Apidologie. 2009;40(3):237-62. http://dx.doi.org/10.1051/apido/2009026.

10. The National Animal Genetic Resources Committee. Animal genetic resources in China bees. Beijing: China Agriculture Press; 2011.

11. Bai Y, Dong JJ, Guan DL, Xie JY, Xu SQ. Geographic variation in wing size and shape of the grasshopper Trilophidia annulata (Orthoptera: Oedipodidae): morphological trait variations follow an ecogeographical rule. Sci Rep. 2016;6:32680. http://dx.doi.org/10.1038/ srep32680

12. Ning Y, Duan C, Chang QQ, Hou XH. Geometric morphometric analysis of wing shape variation and the genetic relationships of six species of the subgenus Culicoides (Diptera: Ceratopogonidae). Journal of Environmental Entomology. 2020;42(1):147-51. http://dx.doi.org/10.1603/me10110.

13. Shevtsova E, Hansson C, Janzen DH, Kjaerandsen J. Stable structural color patterns displayed on transparent insect wings. Proc Natl Acad Sci USA. 2011;108(2):668-73. https://doi.org/10.1073/pnas.1017393108.

14. Francoy TM, Wittmann D, Drauschke M, Müller S, Steinhage V, Bezerra-Laure MAF, De Jong D, Gonçalves LS. Identification of Africanized honey bees through wing morphometrics: two fast and efficient procedures. Apidologie. 2008;39(5):488-94. https://doi.org/10.1051/apido:2008028.

15. Tofilski A. Using geometric morphometrics and standard morphometry to discriminate three honeybee subspecies. Apidologie. 2008;39(5):558-63. https://doi.org/10.1051/apido:2008037.

16. Eimanifar A, Brooks SA, Bustamante T, Ellis JD. Population genomics and morphometric assignment of western honey bees (Apis mellifera L.) in the Republic of South Africa. BMC Genomics. 2018;19(1):615. https://doi.org/10.1186/s12864-018-4998-x.

17. Büchler R, Costa C, Hatjina F, Andonov S, Meixner MD, Conte YL, Uzunov A, Berg S, Bienkowska M, Bouga M et al. The influence of genetic origin and its interaction with environmental effects on the survival of Apis mellifera L. colonies in Europe. Journal of Apicultural Research. 2014;53(2):205-14. https://doi.org/10.3896/IBRA.1.53.2.03.

18. Meixner MD, Büchler R, Costa C, Francis RM, Hatjina F, Kryger P, Uzunov A, Carreck NL. Honey bee genotypes and the environment. Journal of Apicultural Research. 2015;53(2):183-7. http://dx.doi.org/10.3896/IBRA.1.53.2.07.

19. Zammit-Mangion M, Meixner M, Mifsud D, Sammut S, Camilleri L. Thorough morphological and genetic evidence confirm the existence of the endemic honey bee of the Maltese Islands Apis mellifera ruttneri: recommendations for conservation. Journal of Apicultural Research. 2017;56(5):514-22. https://doi.org/10.1080/00218839.2017.1371522.

20. Chen C, Wang HH, Liu ZG, Chen X, Tang J, Meng F, Shi W. Population genomics provide insights into the evolution and adaptation of the eastern honey bee (Apis cerana). Mol Biol Evol. 2018;35(9):2260-71. https://doi.org/10.1093/molbev/msy130.

21. Gauld I, Bolton B. The Hymenoptera. Oxford: Oxford University Press; 1988. 
22. Alexander DH, Novembre J, Lange K. Fast model-based estimation of ancestry in unrelated individuals. Genome Res. 2009;19(9):1655-64. https://doi.org/10.1101/gr.094052.109.

23. Yang J, Lee SH, Goddard ME, Visscher PM. GCTA: a tool for genome-wide complex trait analysis. Am J Hum Genet. 2011;88(1):76-82. https://doi.org/10.1016/j.ajhg.2010.11.011.

24. Wallberg A, Schoning C, Webster MT, Hasselmann M. Two extended haplotype blocks are associated with adaptation to high altitude habitats in East African honey bees. PLoS Genet. 2017;13(5):e1006792. https://doi.org/10.1371/journal.pgen.1006792.

25. Wright S. Evolution and the genetics of populations. Chicago: University of Chicago Press; 1978.

26. Li YC, Chao TL, Fan YH, Lou DL, Wang GZ. Population genomics and morphological features underlying the adaptive evolution of the eastern honey bee (Apis cerana). BMC Genomics. 2019;20(1):869. https://doi.org/10.1186/s12864-019-6246-4.

27. $\mathrm{Li} \mathrm{H}$, Durbin $\mathrm{R}$. Inference of human population history from individual whole-genome sequences. Nature. 2011;475(7357):493-6. https://doi.org/10.1038/nature10231.

28. Whitfield CW, Behura SK, Berlocher SH, Clark AG, Johnston JS, Sheppard WS, Smith DR, Suarez AV, Weaver D, Tsutsui ND. Thrice out of Africa: ancient and recent expansions of the honey bee, Apis mellifera. Science. 2006;314(5799):642-45. https://doi.org/10.1126/science.1132772.

29. Fan QC, SUi JL, Wang TH, Li N, Sun Q. Eurption history and magma evolution of the trachybasalt in the Tianchi volcano, Changbaishan. Acta Petrologica Sinica. 2006;22(6):1449-57. https://doi.org/10.3321/j.issn:1000-0569.2006.06.001.

30. Wang ZB, Wang JY, Li BJ. Copupling relation between cyclic eruption of Quaternary volcano and ancient glacier in Tianchi, Changbai Mts. East China Geology. 2020;41(2):108-15. https://doi.org/10.16788/j.hddz.32-1865/P.2020.02.002.

31. Li JJ. Glacial relics of monsoonal Asia in the last glaciation. Quaternary Sciences. 1992;(4):332-40. https://doi.org/CNKI:SUN:DSJJ.0.1992-04-004.

32. Terhorst J, Kamm JA, Song YS. Robust and scalable inference of population history from hundreds of unphased whole genomes. Nat Genet. 2017;49(2):303-9. https://doi.org/10.1038/ng.3748.

33. Ono Y, Aoki T, Hasegawa H, Dali L. Mountain glaciation in Japan and Taiwan at the global Last Glacial Maximum. Quaternary International. 2005;138-139:79-92. https://doi.org/10.1016/j.quaint.2005.02.007.

34. Pan B. Eruptive history of the Changbaishan Tianchi Volcano, China/DPRK, since the Last Pleistocene. Recent Developments in World Seismology. 2017;(11):39-41. https://doi.org/10.1016/j.jvolgeores.2020.106870.

35. Li XQ, Zhao C, Zhou XY. Vegetation pattern of Northeast China during the special periods since the Last Glacial Maximum. Scientia Sinica Terrae. 2019;49(8):1213-30. https://doi.org/CNKI:SUN:JDXK.0.2019-08-004.

36. Wang SW, Cai JN, Zhu JH, Gong DY. Studies on climate change in China. Climatic and Environmental Research. 2002;7(2):137-45. https://doi.org/10.3969/j.issn.1006-9585.2002.02.002.

37. Cui ZX. The study on volcanic eruption and forest conflagration since holocene quaternary in Changbai MT. Geographical Research. 1997;16(1):92-7. https://doi.org/10.11821/yj1997010012.

38. Li JT. Synopsis of research of volcanic disaster concerning Changbai Mountain. Seismological Research of Northeast China. 1998;14(2):59-66. https://doi.org/10.6038/cjg20160314.

39. Machida H, Arai F. Extensive ash falls in and around the Sea of Japan from large late Quaternary eruptions. Journal of Volcanology and Geothermal Research. 1983;18(1-4):151-64. https://doi.org/10.1016/0377-0273(83)90007-0.

40. Sun CQ, Plunkett G, Liu JQ, Zhao HL, Sigl M, McConnell JR, Pilcher JR, Vinther B, Steffensen JP, Hall V. Ash from Changbaishan Millennium eruption recorded in Greenland ice: implications for determining the eruption's timing and impact. Geophysical Research Letters. 2014;41(2):694-701. https://doi.org/10.17521/cjpe.2015.0216.

41. Machida H, Moriwaki H, Zhao DC. The recent major eruption of Changbai Volcano and its environmental effects. Geographical reports of Tokyo Metropolitan University. 1990;(25):1-20.

42. Liu QJ, Wang Z, Wang SX. Effects of recent volcanic eruptions on alpine and subalpine vegetation in the Changbai Moutain. Scientia Geographica Sinica. 1993;13(1):57-61. https://doi.org/10.13249/j.cnki.sgs.1993.01.011.

43. Liu JQ, Chen SS, Guo WF, Sun CQ, Zhang ML, Guo ZF. Research advances in the Mt. Changbai Volcano. Bulletin of Mineralogy, Petrology and Geochemistry. 2015;34(4):710-23. https://doi.org/10.3969/j.issn.1007-2802.2015.04.005.

44. Mu KH, Zhang W, Niu YB, Yan L, Li CC. Research on the climatic change during the Holocene in Northeastern China. Territory \& Natural Resources Study. 2008;(2):48-50. https://doi.org/10.16202/j.cnki.tnrs.2008.02.001.

45. Li WY, Liang YL. Vegetation and environment of the hypsithermal interval of holocene in Eastern Hebei plain. Acta Botanica Sinica. 1985;27(6):640-51. https://doi.org/CNKI:SUN:ZWXB.0.1985-06-013.

46. Yu SH, Yang P, Sun T, Qi Q, Wang XQ, Chen XM, Feng Y, Liu BW. Transcriptomic and proteomic analyses on the supercooling ability and mining of antifreeze proteins of the Chinese white wax scale insect. Insect Sci. 2016;23(3):430-37. 
https://doi.org/10.1111/1744-7917.12320.

47. Xu K, Niu QS, Zhao HT, Du YL, Jiang YS. Transcriptomic analysis to uncover genes affecting cold resistance in the Chinese honey bee (Apis cerana cerana). PLoS One. 2017;12(6):e0179922. https://doi.org/10.1371/journal.pone.0179922.

48. Meiri S. Bergmann's rule - what's in a name? Global Ecology and Biogeography. 2011;20(1):203-7. https://doi.org/10.1111/j.1466-8238.2010.00577.x.

49. Eweleit L, Reinhold K. Body size and elevation: do Bergmann's and Rensch's rule apply in the polytypic bushcricket Poecilimon veluchianus? Ecological Entomology. 2014;39(1):133-6. https://doi.org/10.1111/een.12061.

50. Underwood BA. Thermoregulation and energetic decision-making by the honeybees Apis cerana, Apis dorsata and Apis laboriosa. Journal of Experimental Biology. 1991;157:19-34. https://doi.org/10.1242/jeb.157.1.19.

51. Chen C, Liu ZG, Pan Q, Chen X, Wang HH, Guo HK, Liu SD, Lu HF, Tian SL, Li RQ et al. Genomic analyses reveal demographic history and temperate adaptation of the newly discovered honey bee subspecies Apis mellifera sinisxinyuan n. ssp. Mol Biol Evol. 2016;33(5):1337-48. https://doi.org/10.1093/molbev/msw017.

52. Bai Y, Dong FD, Bao KO, Qiu AN, Liang RJ, Wang H. Using geometric morphometrics to quantify the sexual dimorphism of Pantala flavescens. Chinese Journal of Applied Entomology. 2015;52(2):363-9. https://doi.org/10.7679/j.issn.2095 1353.2015.040.

53. Greenleaf SS, Williams NM, Winfree R, Kremen C. Bee foraging ranges and their relationship to body size. Oecologia. 2007;153(3): 589-96. https://doi.org/10.1007/s00442-007-0752-9.

54. Abou-Shaara HF, Ahmed ME. Characterisation and tracking changes of morphological characteristics in honey bee, Apis mellifera, Journal of Entomological and Acarological Research. 2015;47(3). https://doi.org/10.1016/j.sjbs.2021.02.050.

55. Zhu X, Zhou S, Xu X, Wang J, Yu Y, Yang K-c, Luo Q, Xu Y, Wang S, Zhou B. Morphological differentiation in Asian honey bee (Apis cerana) populations in the basin and highlands of southwestern China. Journal of Apicultural Research. 2017;56(3):203-9. http://dx.doi.org/10.1080/00218839.2017.1306374.

56. Hoffmann AA, Sgro CM. Climate change and evolutionary adaptation. Nature. 2011;470(7335):479-85. https://doi.org/10.1038/nature09670.

57. Romero ML, Colombo PC, Remis MI. Morphometric differentiation in Cornops aquaticum (Orthoptera: Acrididae): associations with sex, Chromosome, and Geographic Conditions. Journal of Insect Science. 2014;14(164):1-8. https://doi.org/10.1093/jisesa/ieu026.

58. Jongerius SR, Lentink D. Structural Analysis of a Dragonfly Wing. Experimental Mechanics. 2010;50(9):1323-34. https://doi.org/10.1007/s11340-010-9411-x.

59. Zhou SJ, Zhu XJ, Xu XJ, Zheng XJ, Zhou BF. Assessing of Geometric Morphometrics Analyses in Microtaxonomy of the Apis cerana Fabricius (Hymenoptera: Apidae) within China. Journal of the Kansas Entomological Society. 2016;89(4):297-305. https://doi.org/10.2317/0022-8567-89.4.297.

60. Zhou BF, Zhu XJ, Li Y. New mutations in hind wing vein of Apis cerana cerana (Hymenoptera: Apidae) induced by lower developmental temperature. Acta Ecologica Sinica. 2011;31(5):1387-92.https://doi.org/CNKI:SUN:STXB.0.2011-05-023.

61. Zhou BF, Li Y, Zhu XJ, Chen WF, Zhou Y, Zhang X, Chen YH. The effect of temperature during sealed brood period on the vein of the honeybee forewing. Apiculture of China. 2007;58(5):5-8. https://doi.org/CNKI:SUN:ZGYF.0.2007-05-001.

62. Gloag R, Ding G, Christie JR, Buchmann G, Beekman M, Oldroyd BP. An invasive social insect overcomes genetic load at the sex locus. Nat Ecol Evol. 2016;1(1):11. https://doi.org/10.1038/s41559-016-0011.

63. Tan K, Ge FC, Zhao R, He SY. Morphometric characters of Changbaishan A. cerana. Journal of Bee. 2004;(6):8-9. https://doi.org/10.3969/j.issn.1003-9139.2004.06.002.

64. Zhang LJ, Fan X, Tan K, He SY. Morphometric study of Apis cerana in Changbai Moutain. Journal of Yunnan Agricultural University. 2006;21(4):511-6. https://doi.org/10.16211/j.issn.1004-390x(n).2006.04.024.

65. Hao LN, Zhou SJ, Zhu XJ, Xu XJ, Cai ZB, Niu QS, Yuan CY, Chen DH, Zhou BF. Genetic differentiation and genetic diversity analysis of Apis cerana in northeast China. Journal of Northeast Agricultural University. 2019;50(9):35-43. https://doi.org/10.19720/j.cnki.issn.1005-9369.2019.09.005.

66. Ji YK, Li XA, Ji T, Tang JB, Qiu LF, Hu JH, Dong JX, Luo SQ, Liu SL, Frandsen PB, et al. Gene reuse facilitates rapid radiation and independent adaptation to diverse habitats in the Asian honeybee. Science Advances. 2020;6(51):eabd3590. https://doi.org/10.1126/sciadv.abd3590.

67. Choe SE, Nguyen TT, Hyun BH, Noh JH, Lee HS, Lee CH, Kang SW. Genetic and phylogenetic analysis of South Korean sacbrood virus isolates from infected honey bees (Apis cerana). Vet Microbiol. 2012;157:32-40. https://doi.org/10.1016/j.vetmic.2011.12.007.

68. Park D, Jung JW, Choi BS, Jayakodi M, Lee J, Lim J, Yu Y, Choi YS, Lee ML, Park Y et al. Uncovering the novel 
characteristics of Asian honey bee, Apis cerana, by whole genome sequencing. BMC Genomics. 2015;16:1-16. https://doi.org/10.1186/1471-2164-16-1.

69. Yu YL, Zhou SJ, Xu XJ, Zhu XJ, Zhou BF. Analysis on genetic diversity of Apis cerana cerana in Changbai Mountains. Journal of Fujian Apiculture and Forestry University (Nature Science Edition). 2013;42(6):643-7. https://doi.org/10.13323/j.cnki.j.fafu(nat.sci.).2013.06.021.

70. Gao FC. Study on genetic diversity of Apis cerana cerana populations from Changbai Mountain by microsatellite makers. Apiculture of China. 2015;66(7):20-2. https://doi.org/CNKI:SUN:ZGYF.0.2015-07-008.

71. Pesenko YA, Lelej AS, Radchenko VG, Filatkin GN. The Chinese wax bee Apis cerana cerana F. (Hymenoptera, Apidae) in the Soviet Far East. Entomological Review. 1990;69(3):21-46.

72. Hepburn HR, Smith DR, Radloff SE, Otis GW. Infraspecific categories of Apis cerana: morphometric, allozymal and mtDNA diversity. Apidologie. 2001;32(1):3-23. https://doi.org/10.1051/apido/2010008.

73. Jing XH, Kang L. Geographical variation in egg cold hardiness: a study on the adaptation strategies of the migratory locust Locusta migratoria L. Ecological Entomology. 2003;28:151-58. https://doi.org/10.1046/j.1365-2311.2003.00497.x.

74. Harpur BA, Kent CF, Molodtsova D, Lebon JM, Alqarni AS, Owayss AA, Zayed A. Population genomics of the honey bee reveals strong signatures of positive selection on worker traits. Proceedings of the National Academy of Sciences of the United States of America. 2014;111(7):2614-9. https://doi.org/10.1073/pnas.1315506111.

75. Plate M, Bernstein R, Hoppe A, Bienefeld K. Long-term evaluation of breeding scheme alternatives for endangered honeybee subspecies. Insects. 2020;11(7). https://doi.org/10.3390/insects11070404.

76. De la Rúa P, Jaffé R, Dall'Olio R, Muñoz I, Serrano J. Biodiversity, conservation and current threats to European honeybees. Apidologie. 2009;40(3):263-84. https://doi.org/10.1186/s12711-019-0518-y.

77. Muñoz I, Henriques D, Jara L, Johnston JS, Chavez-Galarza J, De La Rua P, Pinto MA. SNPs selected by information content outperform randomly selected microsatellite loci for delineating genetic identification and introgression in the endangered dark European honeybee (Apis mellifera mellifera). Mol Ecol Resour. 2017;17(4):783-95. https://doi.org/10.1111/1755-0998.12637.

78. Rohlf, FJ. tpsUtil, version 1.40. Department of Ecology and Evolution, State University of New York; Stony Brook, New York; 2008a.

79. Rohlf, FJ. tpsDIG, version 2.11. Department of Ecology and Evolution, State University of New York; Stony Brook, New York; 2008b.

80. Qiu LF, Wei ZM, Wang JJ, Liu HX, Zhao BX, Zhang Y, Lian ZM. Geometric analysis of morphological variation in the wing of Apis cerana cerana from the Qinling-Daba Mountain Areas. Chinese Journal of Applied Entomology. 2018;55(3):503-13. https://doi.org/10.7679/j.issn.2095-1353.2018.064.

81. Bai Yi, Dai DF, Bao KO, Qiu AN, Liang RJ, Wang HR. Using geometric morphometrics to quantify the sexual dimorphism of Pantala flavescens. Chinese Journal of Applied Entomology. 2015;52(2):363-9. https://doi.org/10.7679/j.issn.2095-1353.2015.040.

82. Li H, Durbin R. Fast and accurate short read alignment with Burrows-Wheeler transform. Bioinformatics. 2009;25(14):1754-60. https://doi.org/10.1093/bioinformatics/btp324.

83. Diao Q, Sun L, Zheng H, Zeng Z, Wang S, Xu S, Zheng H, Chen Y, Shi Y, Wang Y et al. Genomic and transcriptomic analysis of the Asian honeybee Apis cerana provides novel insights into honeybee biology. Sci Rep. 2018;8(1):822. https://doi.org/10.1038/s41598-017-17338-6.

84. Li H, Handsaker B, Wysoker A, Fennell T, Ruan J, Homer N, Marth G, Abecasis G, Durbin R. Genome project data processing S: The sequence alignment/map format and SAMtools. Bioinformatics. 2009;25(16):2078-9. https://doi.org/10.1093/bioinformatics/btp352. 


\section{Figure Legends:}

Fig. 1 Boxplot of CS of A. cerana in wing size across geographical populations. (A) Centroid size of forewing of A. cerana. (B) Centroid size of hindwing of $A$. cerana

Fig. 2 The TPS result of forewing and hindwing of A. cerana populations in Changbai Mountain (BS population). (A) Forewing. (B) Hindwing

Fig. 3 Geographic locations of the sampled bees in China. The sampling location of the Changbai Mountain area is highlighted as a yellow enlarged area map. Triangles represent the sampling locations of the samples downloaded; circles represent the sampling locations of the samples from northern, southern, northwestern, and Qinghai-Tibetan regions; and stars represent the sampling locations of the samples from Changbai Mountain

Fig. 4 PCA results. (A) Genetic structure of $A$. cerana populations from 5 districts. Groupings of samples from two to five ancestral clusters are shown. (B) Scatter plot of PC1 versus PC2 for the A. cerana populations. (C) Neighbour-joining phylogenetic tree with $A$. mellifera as an outgroup.

Fig. 5 The result of nucleotide diversity $(\pi)$. (A) A. cerana populations from five districts. (B) A. cerana populations in Changbai Mountain

Fig. 6 The analysis of LD for A. cerana populations

Fig. 7 Effective population size of $A$. cerana populations. Red line represents the effective population size of an $A$. cerana population in Changbai Mountain. (A) PSMC; (B) SMC++

Fig. 8 (A) Plot of the selection elimination analysis between the A. cerana population in Changbai Mountain and the $A$. cerana population in Hainan based on Fst and $\theta \pi$. The horizontal coordinates are the $\theta \pi$ ratio values and the vertical coordinates are the Fst values, which correspond to the frequency distribution plot above and the frequency distribution plot on the right, respectively, and the dot plots in the middle represent the corresponding Fst and $\theta \pi$ ratio values in different windows, where the blue and green areas are the top $5 \%$ areas selected by $\theta \pi$ and the red areas are the top 5\% areas selected by Fst; (B) A selection elimination analysis plot based on Fst and $\theta \pi$ for A. cerana in Changbai Mountain and Tibet

Fig. 9 Location of the geometric landmarks on the wing of A. ceranain in Changbai Mountain. (A) 20 landmarks on the right forewing; the red circle is the small protrusion vein on the radiomedial crossvein.(B) 10 landmarks on the right hindwing

\section{Form description}

Table 1 Paired Fst genetic distances between A. cerana populations

Table 2 Paired Fst genetic distances between A. cerana populations in Changbai Mountain

Table 3 Genetic diversity information of $A$. cerana populations 
Figures

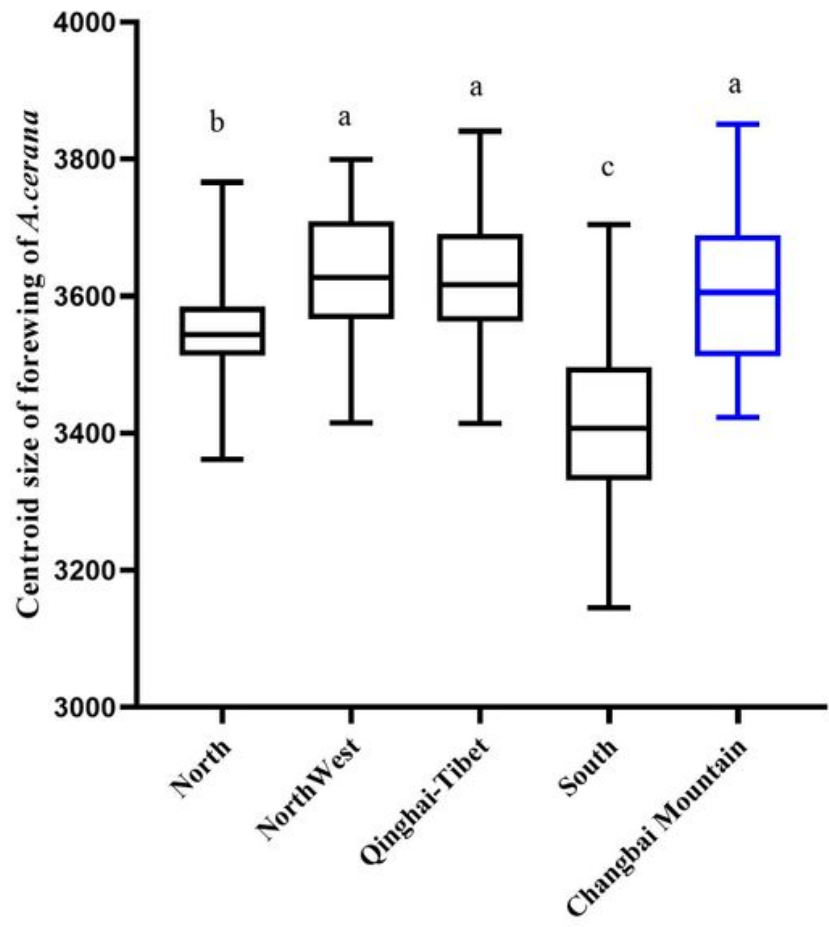

B

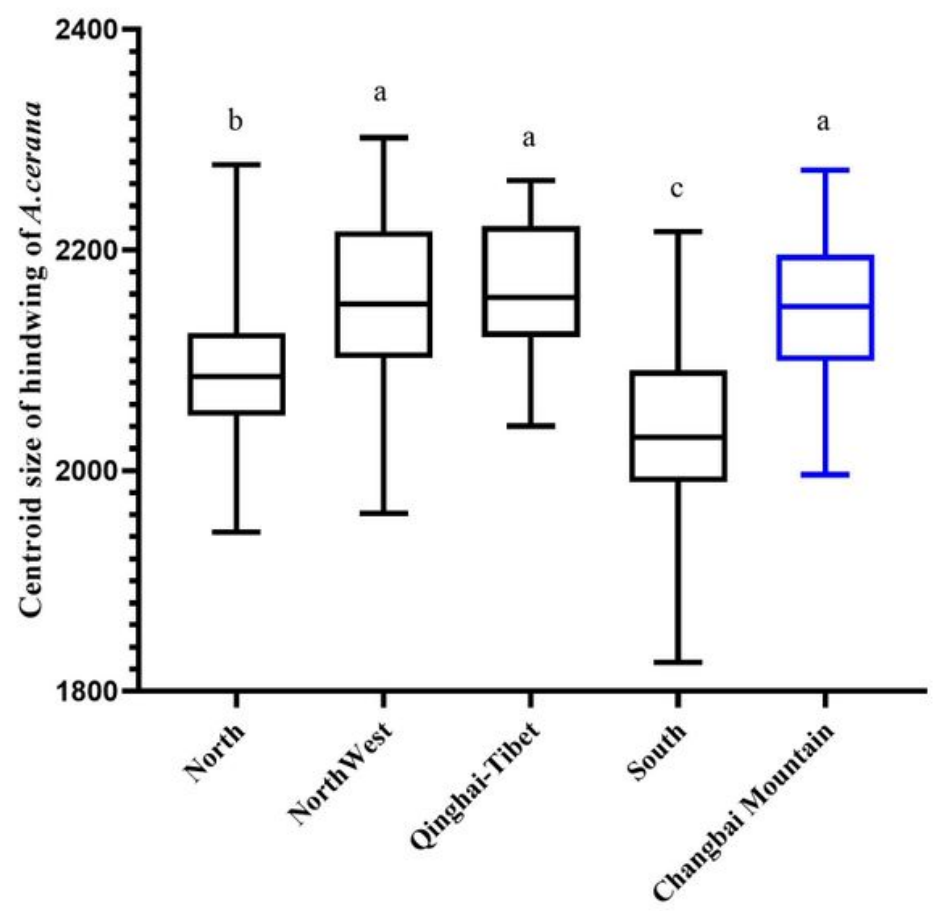

Figure 1

Boxplot of CS of A. cerana in wing size across geographical populations. (A) Centroid size of forewing of A. cerana. (B) Centroid size of hindwing of A. cerana 


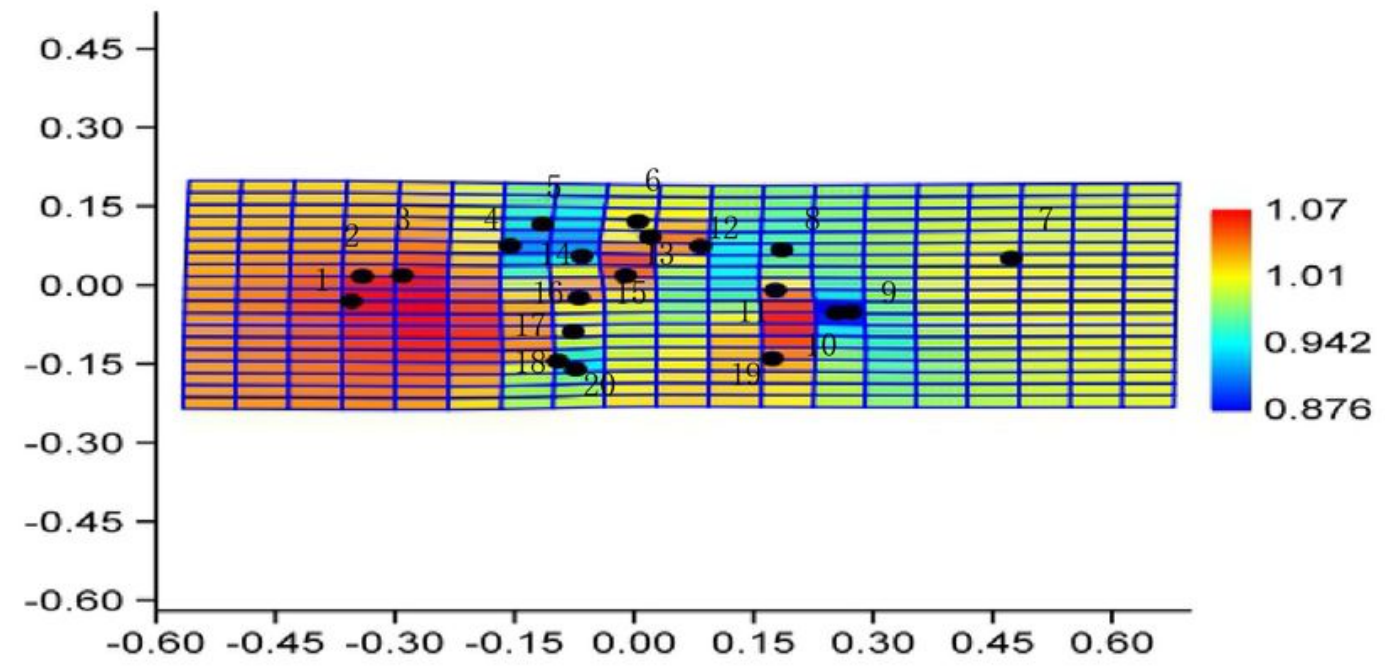

B

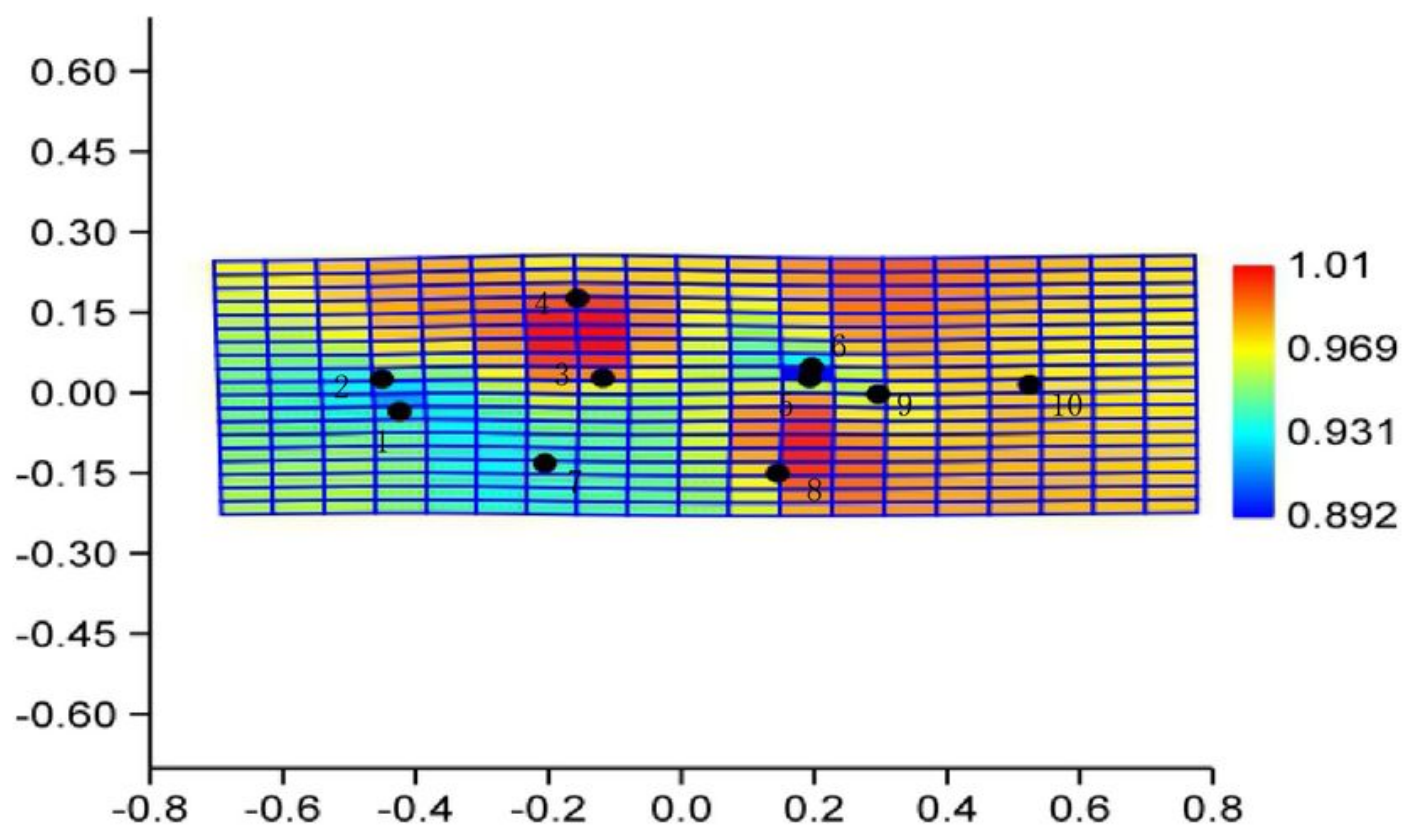

Figure 2

The TPS result of forewing and hindwing of A. cerana populations in Changbai Mountain (BS population). (A) Forewing. (B) Hindwing 


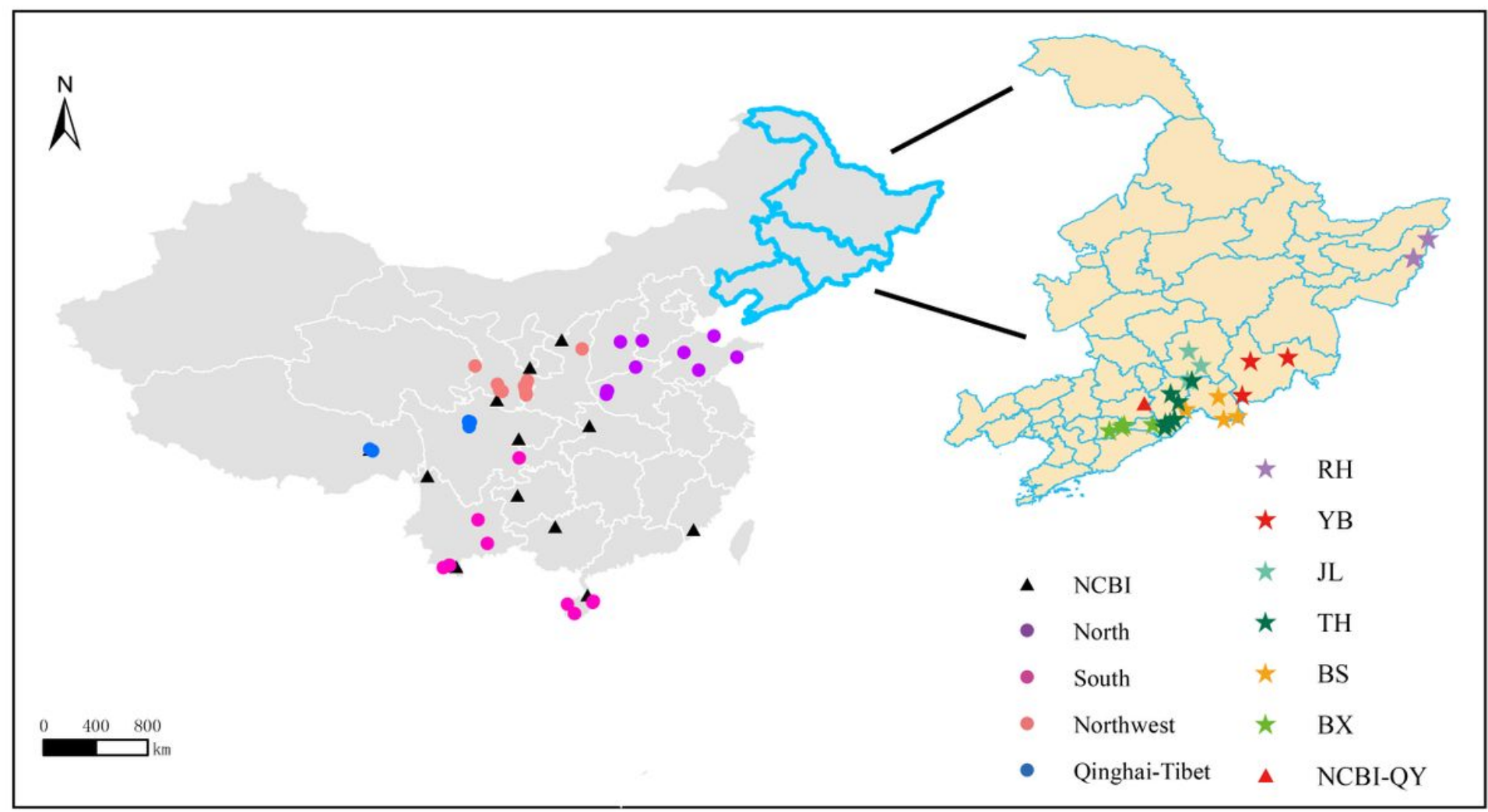

\section{Figure 3}

Geographic locations of the sampled bees in China. The sampling location of the Changbai Mountain area is highlighted as a yellow enlarged area map. Triangles represent the sampling locations of the samples downloaded; circles represent the sampling locations of the samples from northern, southern, northwestern, and Qinghai-Tibetan regions; and stars represent the sampling locations of the samples from Changbai Mountain Note: The designations employed and the presentation of the material on this map do not imply the expression of any opinion whatsoever on the part of Research Square concerning the legal status of any country, territory, city or area or of its authorities, or concerning the delimitation of its frontiers or boundaries. This map has been provided by the authors. 
A

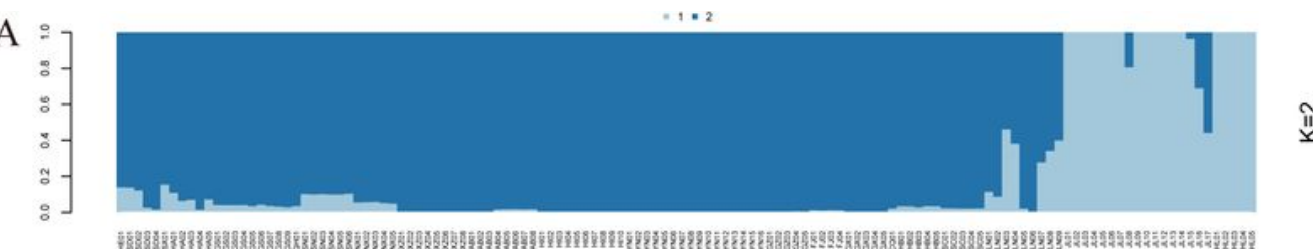

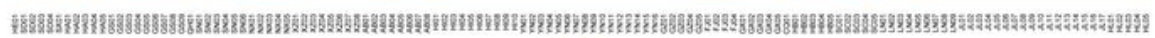

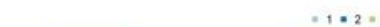

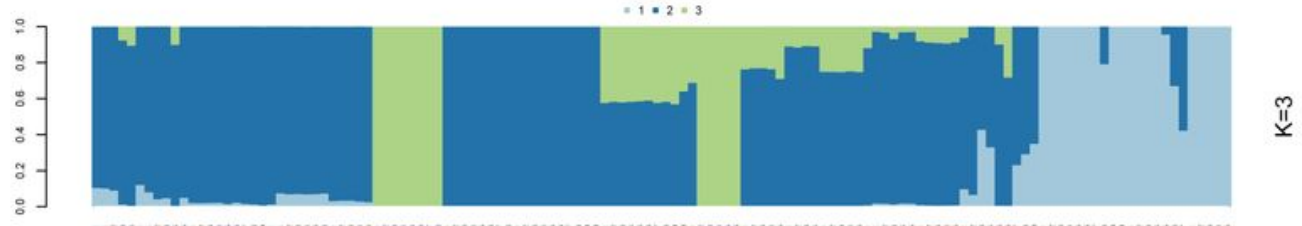

ธุ.

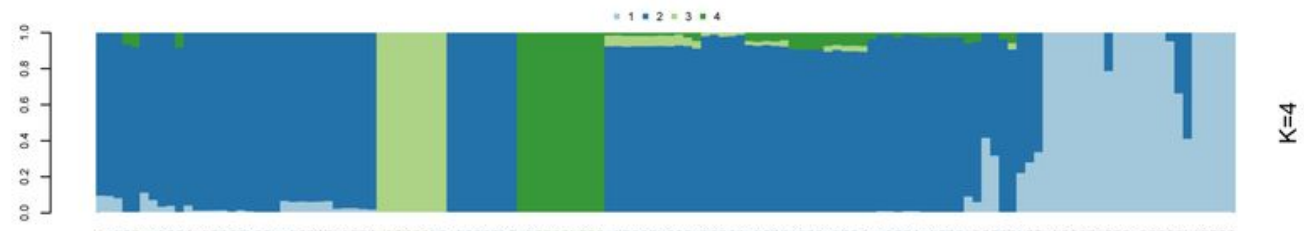

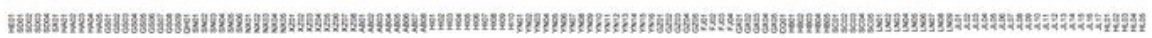

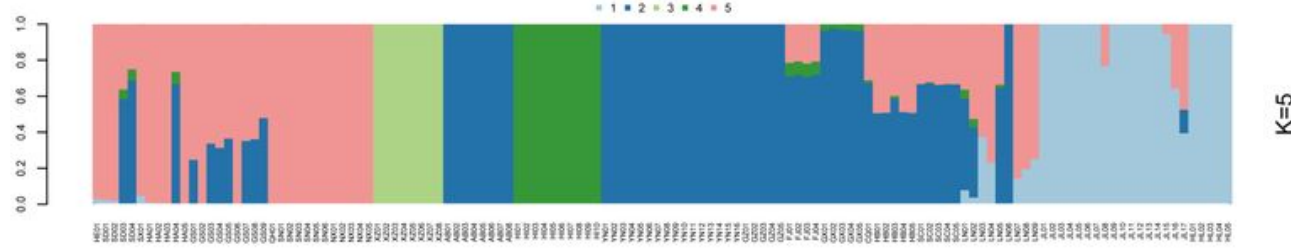

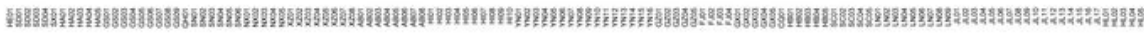
North NorthWest Qinghai-Tibet
South
Changbai Mountain

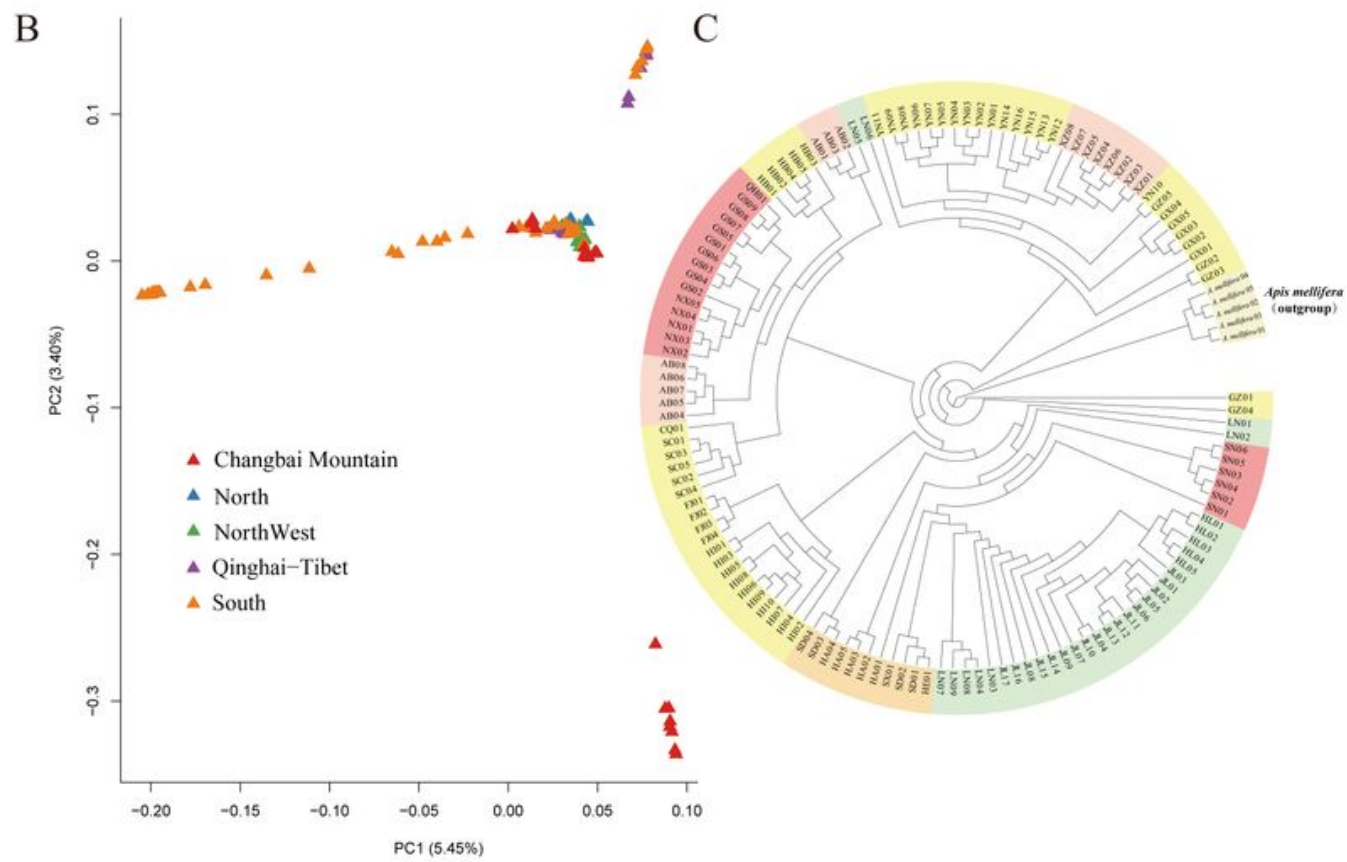

\section{Figure 4}

PCA results. (A) Genetic structure of A. cerana populations from 5 districts. Groupings of samples from two to five ancestral clusters are shown. (B) Scatter plot of PC1 versus PC2 for the A. cerana populations. (C) Neighbour-joining phylogenetic tree with A. mellifera as an outgroup. 
A

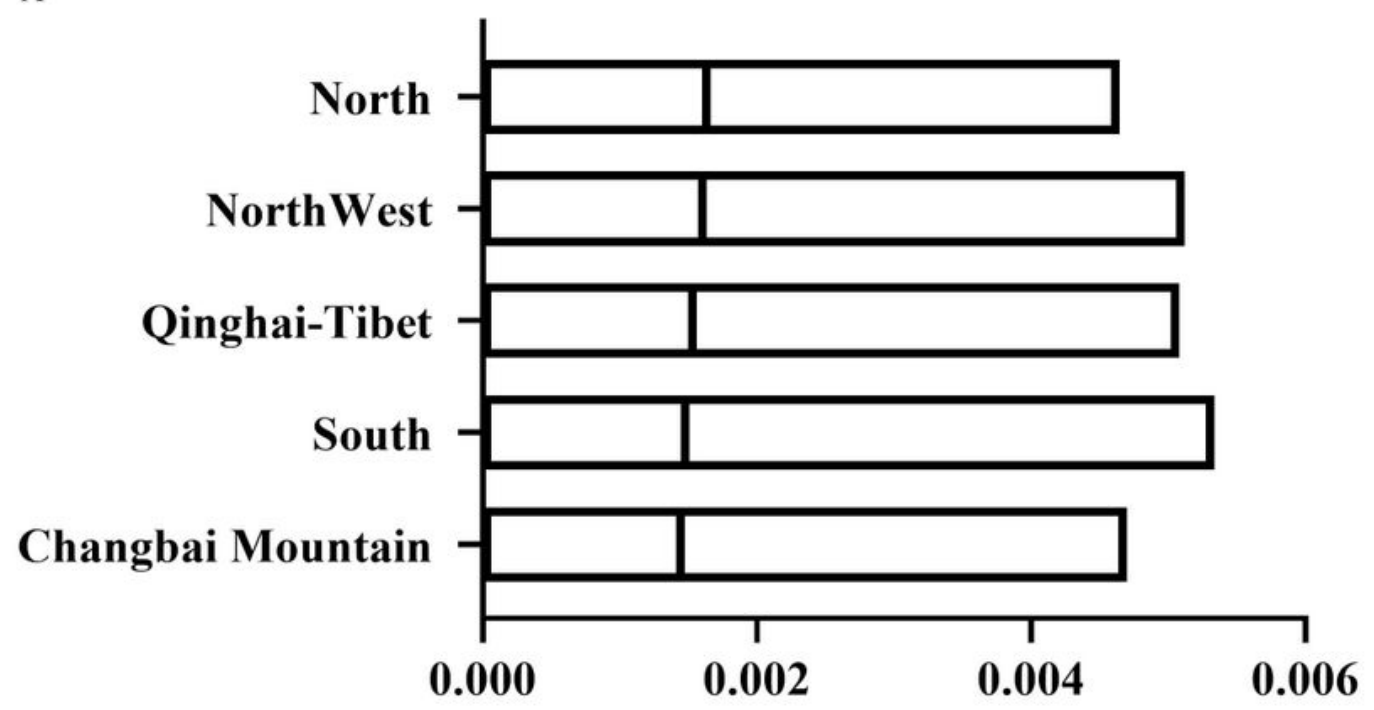

Nucleotide diversity $\pi$

B

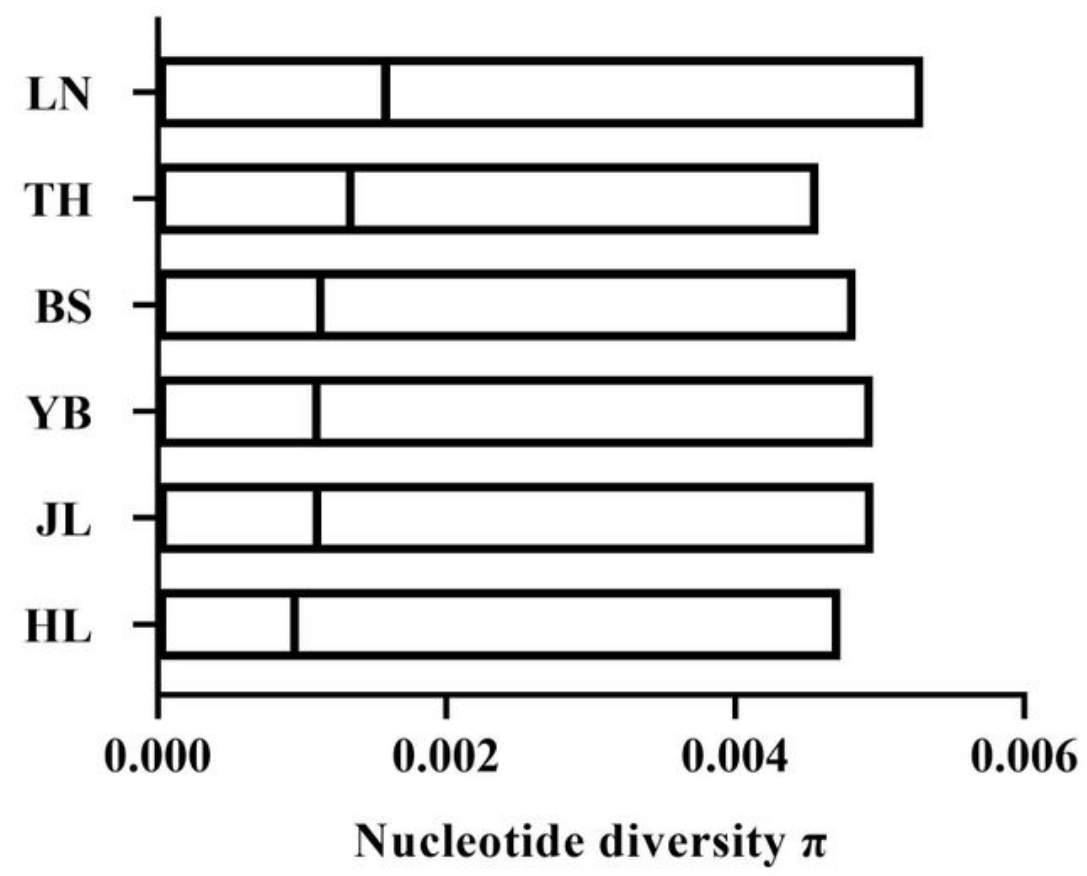

Figure 5

The result of nucleotide diversity $(\pi)$. (A) A. cerana populations from five districts. (B) A. cerana populations in Changbai Mountain 


\section{LD decay}

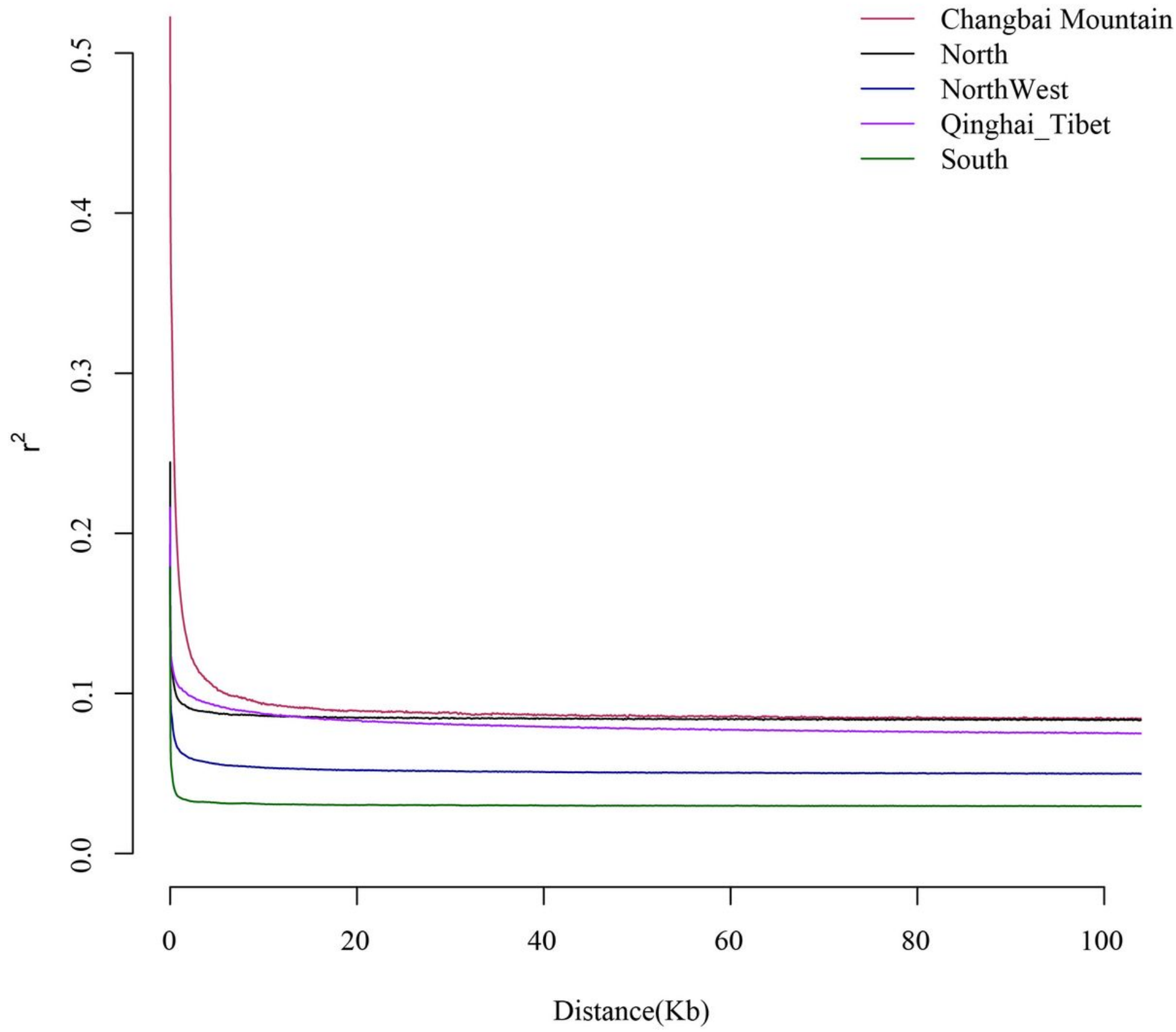

Figure 6

The analysis of LD for A. cerana populations 
A

PSMC Plot

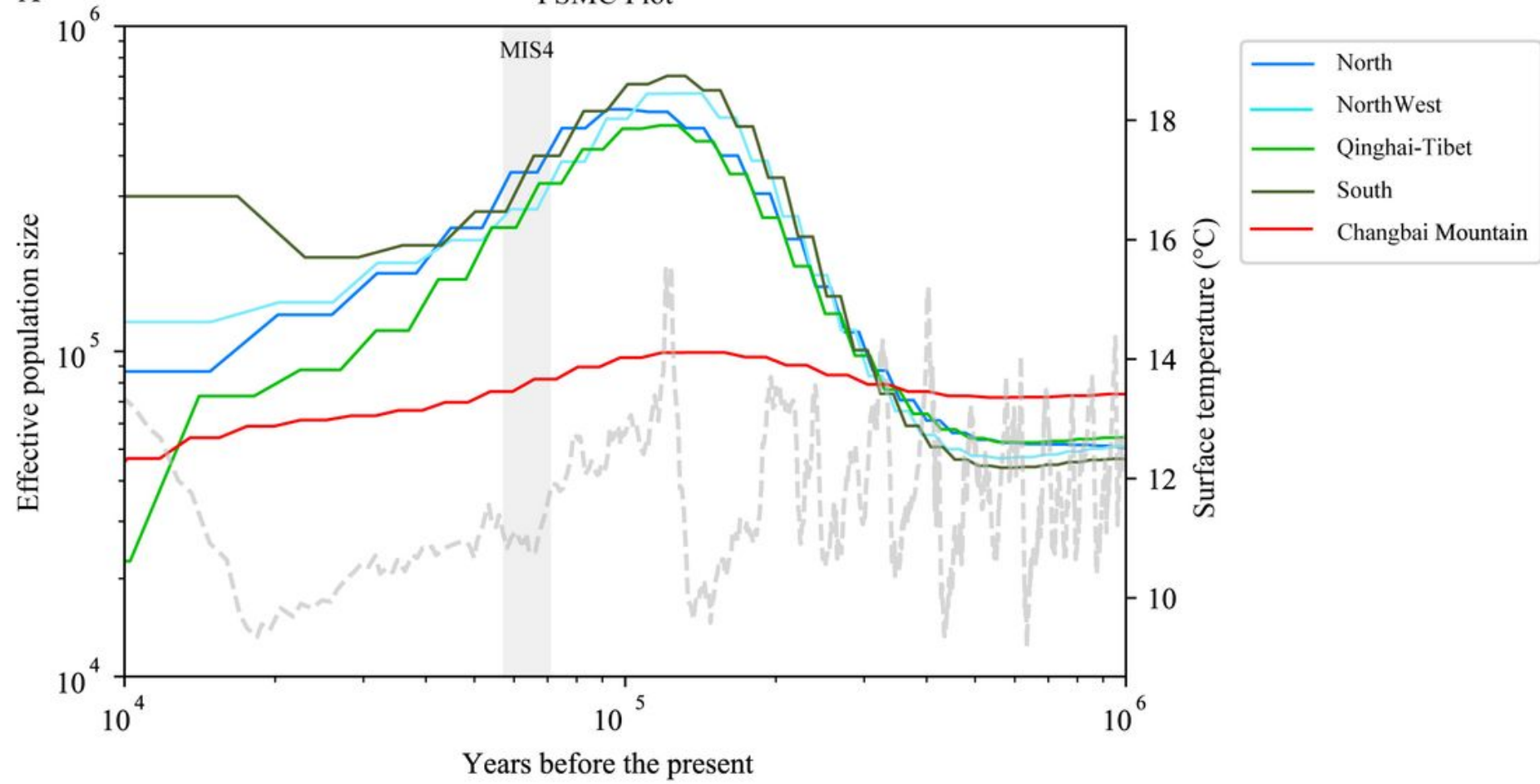

B $\quad$ SMC++ Plot

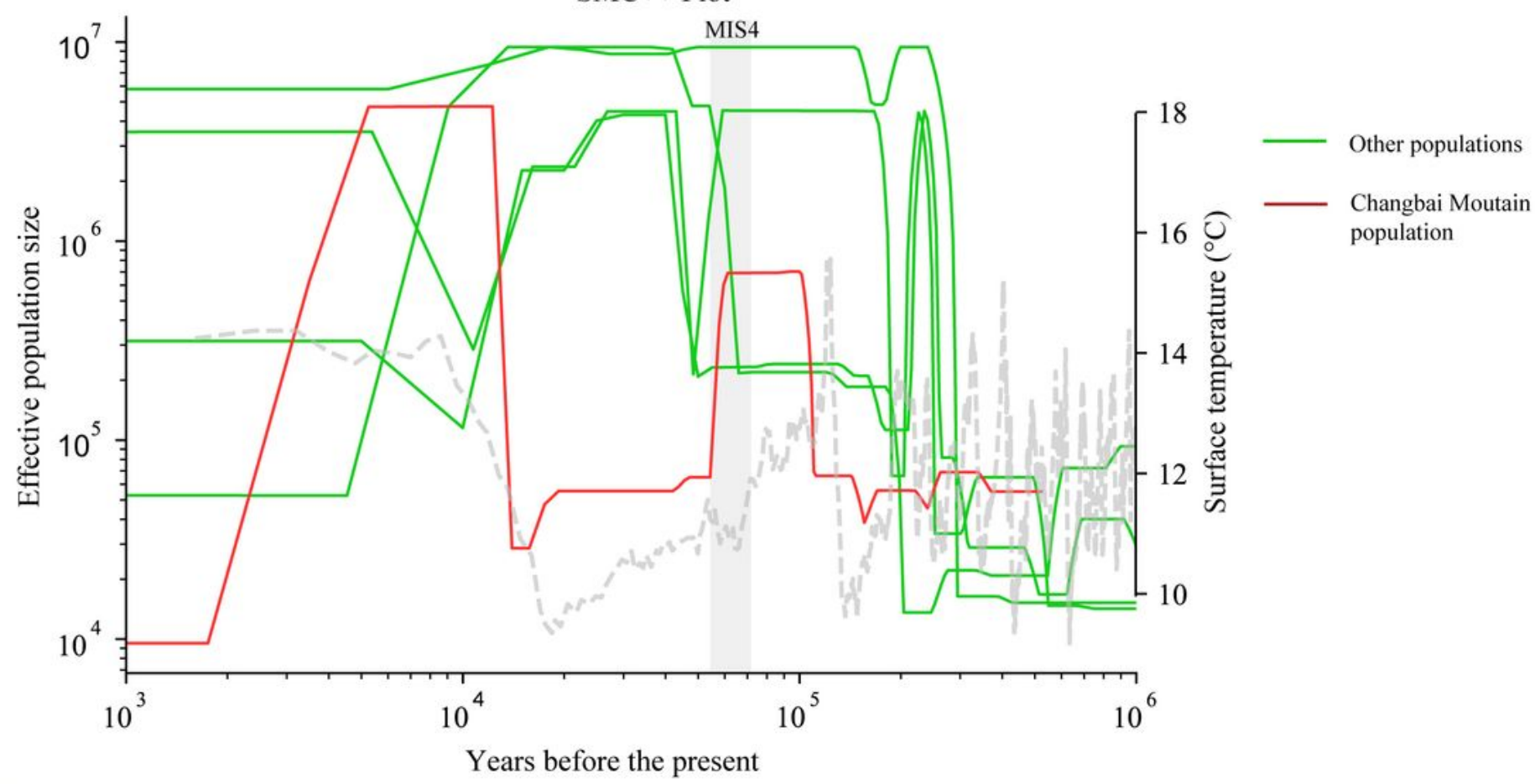

Figure 7

Effective population size of A. cerana populations. Red line represents the effective population size of an A. cerana population in Changbai Mountain. (A) PSMC; (B) SMC++ 

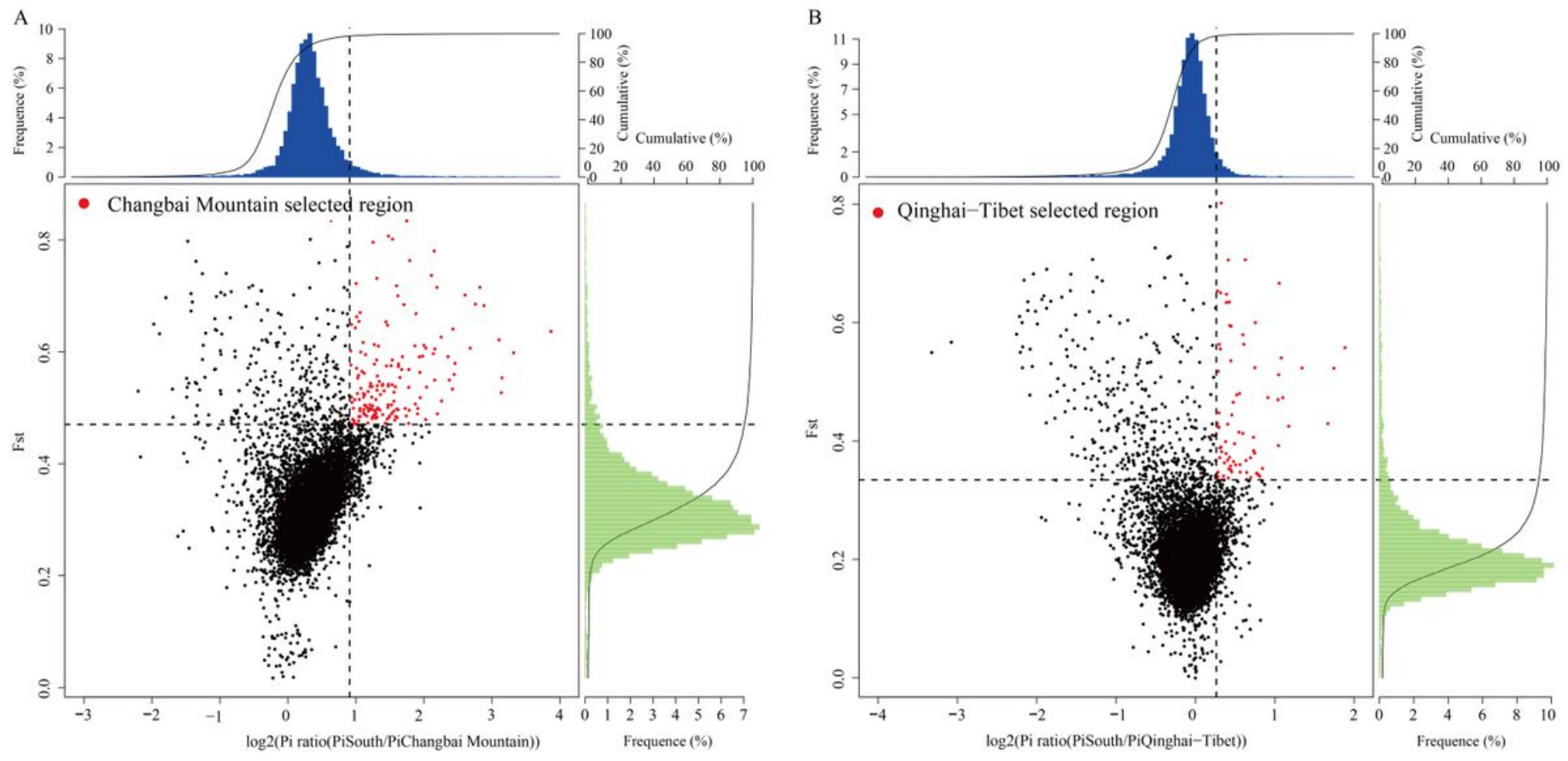

Figure 8

(A) Plot of the selection elimination analysis between the A. cerana population in Changbai Mountain and the A. cerana population in Hainan based on Fst and $\theta \pi$. The horizontal coordinates are the $\theta \pi$ ratio values and the vertical coordinates are the Fst values, which correspond to the frequency distribution plot above and the frequency distribution plot on the right, respectively, and the dot plots in the middle represent the corresponding Fst and $\theta \pi$ ratio values in different windows, where the blue and green areas are the top $5 \%$ areas selected by $\theta \pi$ and the red areas are the top $5 \%$ areas selected by Fst; (B) A selection elimination analysis plot based on Fst and $\theta \pi$ for A. cerana in Changbai Mountain and Tibet 

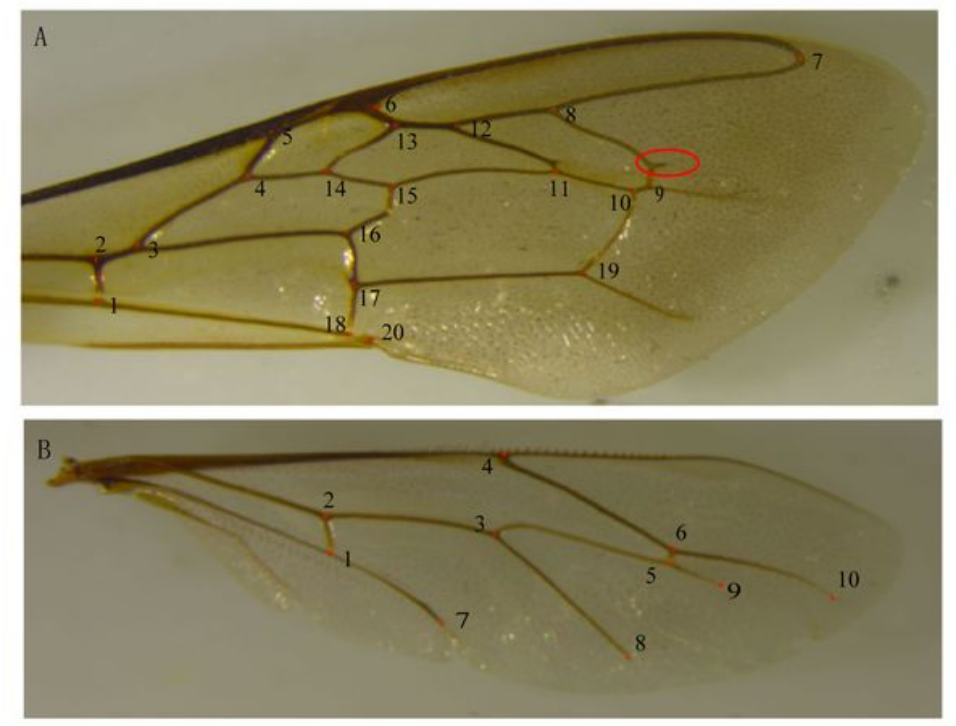

\section{Figure 9}

Location of the geometric landmarks on the wing of A. ceranain in Changbai Mountain. (A) 20 landmarks on the right forewing; the red circle is the small protrusion vein on the radiomedial crossvein.(B) 10 landmarks on the right hindwing

\section{Supplementary Files}

This is a list of supplementary files associated with this preprint. Click to download.

- Additionalfile1TableS1S2.xlsx

- Additionalfile4TableS3.xIsx

- Additionalfile5TableS4.xIsx

- Additionalfile6Tables5.xlsx

- Additionalfile7TableS6S7.xlsx

- Additionalfile9Tables8.xlsx 
- Additionalfile10TableS9S10.xIsx

- Additionalfile11TableS11.xlsx

- Additionalfile12TableS12.xlsx

- Additionalfile2Figures1.pdf

- Additionalfile3Figures2.pdf

- Additionalfile8Figures3.pdf

- Table1.pdf

- Table2.pdf

- Table3.pdf 